The University of Southern Mississippi

The Aquila Digital Community

Faculty Publications

$10-10-2018$

\title{
Unexpected Effects of Inorganic Phosphate Glass On Crystallization and Thermo-Rheological Behavior of Polyethylene Terephthalate
}

Kyoungtae Kim

University of Southern Mississippi

Shahab Kashani Rahimi

University of Southern Mississippi

Todd M. Alam

Sandia National Laboratories

Eric G. Sorte

Sandia National Laboratories

Joshua U. Otaigbe

University of Southern Mississippi, joshua.otaigbe@usm.edu

Follow this and additional works at: https://aquila.usm.edu/fac_pubs

Part of the Polymer Chemistry Commons

\section{Recommended Citation}

Kim, K., Rahimi, S. K., Alam, T. M., Sorte, E. G., Otaigbe, J. U. (2018). Unexpected Effects of Inorganic Phosphate Glass On Crystallization and Thermo-Rheological Behavior of Polyethylene Terephthalate. Polymer, 154, 135-147.

Available at: https://aquila.usm.edu/fac_pubs/16934

This Article is brought to you for free and open access by The Aquila Digital Community. It has been accepted for inclusion in Faculty Publications by an authorized administrator of The Aquila Digital Community. For more information, please contact Joshua.Cromwell@usm.edu. 


\title{
Unexpected effects of inorganic phosphate glass on crystallization and thermo-rheological behavior of polyethylene terephthalate
}

\author{
Kyoungtae Kim ${ }^{a}$, Shahab Kashani Rahimi ${ }^{a}$, Todd M. Alam ${ }^{\text {b }}$, \\ Eric G. Sorte ${ }^{b}$, and Joshua U. Otaigbe ${ }^{a, *}$
}

a School of Polymer Science and Engineering, The University of Southern Mississippi, 118

College Drive, Hattiesburg, Mississippi 39406, United States

b Department of Organic Materials Science, Sandia National Laboratories, Albuquerque, NM 87185, United States

* Corresponding Author: Email address: Joshua.otaigbe@usm.edu

Phone: (601) 266-5596, Fax: (601) 266-5504

Submitted to Polymer, July 9, 2018 


\begin{abstract}
The effects of ultra-low glass transition temperature $\left(T_{g}\right)$ phosphate glass (Pglass) on the thermal, morphological, rheological, mechanical, and crystallization properties of hybrid Pglass/poly(eththylene terephthalate)(PET) were investigated. Nano- and micro-scale distribution of the Pglass in the PET polymer matrix was observed. The polydispersed Pglass in the PET matrix functioned as a nucleation agent, resulting in increasing crystallization temperature. The Pglass in the PET matrix decreased the $T_{g}$, indicating a plasticizing effect of the Pglass in the hybrids that was confirmed by the significantly decreased complex viscosity of the PET matrix. In addition, with increasing temperature, a non-terminal behavior of the viscoelastic properties occurred due to the hybrid structural changes and improved miscibility of the hybrid components. Further, the obtained solid-state variable temperature ${ }^{31} \mathrm{P}$ and ${ }^{1} \mathrm{H}$ NMR spectroscopy results showed strong Pglass concentration dependency of the interactions at the PET-Pglass interface.
\end{abstract}

Keywords: Polyethylene terephthalate, phosphate glass, hybrids, crystallization and nucleation, rheology, solid state NMR. 


\section{Introduction}

Conventional polymer matrix composites are composed of organic polymer matrix and various fillers to improve their mechanical, thermal and rheological properties [1-3] and to costeffectively meet the specific requirements of various industrial applications [4, 5]. However, new technologies are growing fast and often require optimized materials for specific applications where current traditional polymer composites are not useable. Consequently, development of functional organic/inorganic hybrids materials with prescribed properties and functions are needed for a number of industrial uses. Note that hybrid materials are defined as materials with organic and inorganic components, displaying better properties than that of the original components [6-8]. In general, hybrid materials consist of organic polymer materials as the continuous matrix and inorganic materials as the filler that are combined with physical mixing or chemical reaction, resulting in new materials with a microstructure and physicochemical interactions with enhanced benefits in the targeted applications [8].

Poly(ethylene terephthalate) (PET) is a semi-crystalline thermoplastic polyester widely used in various applications such as fiber, films and various injection-molded parts due to its excellent physical properties including chemical resistance, optical clarity, dimensional stability and high strength [9-11]. However, PET exhibits a relatively slow crystallization rate and a low thermal distortion temperature, limiting its extensive applications in injection molding and engineering plastic applications [12-14]. In order to improve the thermal, morphological and mechanical properties of the PET polymer matrix, nanoscale materials such as CNTs [15], clay $[16,17]$, and $\mathrm{SiO}_{2}[18]$ are incorporated into the PET polymer matrix as reported in the literature.

Inorganic phosphate glass is typically used in optical and biomedical applications due to its excellent mechanical properties, optical clarity and biocompatibility $[19,20]$. As an example, a new class of tin fluorophosphates glass (hereinafter referred to as Pglass) can be efficiently combined with organic polymer materials using melt processing methods like extrusion and injection molding to prepare composite materials with improved properties. Pglass has ultra-low $\mathrm{T}_{\mathrm{g}}$ values between $90^{\circ} \mathrm{C}$ to $140^{\circ} \mathrm{C}$, which enables facile mixing and processing of the Pglass with polymer composite components to achieve desired properties already mentioned [6, 19-21]. In this context, Urman et al. [20] reported that Pglass in polyamide 6 affected the crystallization process and properties such as the crystallization growth rate and the percent of crystallinity of the polymer material. Guschl et al. [19] reported that Pglass in a polypropylene (PP) and polyethylene (PE) matrix changed the percentage crystallinity and onset temperature of 
crystallization of the matrix polymers by acting as the polymer crystal nucleation agent in the Pglass/polymer hybrid materials.

In the current study, Pglass was processed with PET using conventional polymer processing methods in the liquid melt state due to the ultra-low $T_{g}$ of Pglass [22]. The morphology of cryo-fractured surfaces of the hybrids and polymer crystals was investigated using microscopic analysis techniques; and isothermal crystallization kinetics were characterized by differential scanning calorimetry (DSC) analysis to understand the thermal behavior of the Pglass/PET hybrid system. The current study reported here is focused on a detailed investigation and analysis of the effects of Pglass molecules in a PET matrix on the thermal, morphological and thermo-rheological properties of the hybrid materials. In particular, the distribution of nano- or micro-sized Pglass particles was investigated to understand the origin of the unique mechanical, crystallization, and rheological properties, making it possible to discover and control mechanisms that develop on nanometer length scales, influence the microscale, and impact the macroscale. In addition, the effect of Pglass content and its correlation with temperature on the rheological and dynamic mechanical properties of the hybrids under test conditions that the materials are likely to encounter during use are discussed. It is hoped that this study will provide a better understanding of the Pglass/PET hybrid materials and other similar organic/inorganic hybrid materials in general.

\section{Experimental Methods}

\subsection{Materials and preparation of hybrids}

The PET (obtained from DAK America) used in this study has a melting point of $240{ }^{\circ} \mathrm{C}$ and intrinsic viscosity of $0.79 \pm 0.02 \mathrm{dl} / \mathrm{g}$. Analytical reagent grade tin(II) oxide (SnO), tin(II) fluoride $\left(\mathrm{SnF}_{2}\right)$ and ammonium dihydrogen phosphate $\left(\left(\mathrm{NH}_{4}\right) \mathrm{H}_{2} \mathrm{PO}_{4}\right)$ were purchased from Sigma-Aldrich and used as received to prepare the tin fluorophosphates glass used in this study. The tin fluorophosphates (Pglass) was synthesized with a molar composition of $50 \mathrm{SnF}_{2}+20 \mathrm{SnO}+$ $30 \mathrm{P}_{2} \mathrm{O}_{5}$ at $430{ }^{\circ} \mathrm{C}$ for $30 \mathrm{~min}$, to yield the Pglass with ultra-low glass transition temperature $\left(\mathrm{T}_{\mathrm{g}}\right)$ about $123^{\circ} \mathrm{C}$ [6]. The Pglass/PET hybrids with various desired concentrations of Pglass ranging from 0 wt. $\%$ to $15 \mathrm{wt}$ \% were prepared using a Thermo-Haake Polydrive ${ }^{\circledR}$ melt mixer equipped with roller rotors. In addition, a sample with $30 \mathrm{wt} \%$ of Pglass was prepared and used exclusively for rheological characterization to magnify the effects of relatively high Pglass content in the polymer matrix. The obtained hybrid materials from the Polydrive ${ }^{\circledR}$ melt mixer were cryo-fractured prior to morphological analysis. A portion of the obtained hybrid materials was compression- 
molded using $40 \mathrm{MPa}$ into thin films at $260^{\circ} \mathrm{C}$ and cooled down with $20^{\circ} \mathrm{C} / \mathrm{min}$ cooling rate for polarized optical micrograph (POM). Some of thin films were ground into powder for ATR-FTIR and solid state NMR analysis. All the hybrid samples were dried over-night to constant weight in a vacuum oven maintained at $80^{\circ} \mathrm{C}$ prior to testing.

\subsection{Measurements}

\subsubsection{Thermal gravimetric analysis (TGA)}

Thermogravimetric analysis (TGA) tests were performed on the samples using a TA instruments Q500 equipment operating from $30^{\circ} \mathrm{C}$ to $600^{\circ} \mathrm{C}$ at a heating rate of $10^{\circ} \mathrm{C} / \mathrm{min}$ under a nitrogen atmosphere. Thermal decomposition temperature was defined as the onset temperature of the thermal degradation of samples, which was obtained using the universal analysis software from TA instruments.

\subsubsection{Scanning electron microscopy (SEM) and Energy Dispersive X-ray spectroscopy (EDX)}

The processed PET (control) and Pglass/PET hybrid samples were cryo-fractured after immersion in liquid nitrogen and subsequently coated with silver using a Quorum ${ }^{\circledR}$ Emitech K550X sputter coater to make the samples conductive for optimal observation of the morphology of the fractured surface of the Pglass/ PET hybrids. A Zeiss Sigma VP ${ }^{\circledR}$ field emission scanning electron microscope (SEM) operating at 20kV with attached energy-dispersive X-ray spectroscopy capability (EDX) and a Thermo Scientific UltraDry EDX detector was utilized to investigate the morphology and elemental compositions on the surfaces of the fractured samples. The obtained elemental data were analyzed using $\mathrm{NSS} 3^{\circledR}$ micro-analysis software.

\subsubsection{Transmission electron microscopy (TEM)}

TEM experiments were performed on a Zeiss $900^{\circledR}$ with an acceleration voltage of $50 \mathrm{kV}$ to identify the homogeneous dispersion of nano- or micro-size Pglass particles in the nanocomposites. The specimens for TEM were prepared by microtome sectioning and the specimen sections were placed in 200 mesh copper grids for observation. 


\subsubsection{Polarized optical microscopy (POM)}

The crystallization behavior of the hybrids was investigated using a Nikon Optihot ${ }^{\circledR}$ optical microscope equipped with a Metler Toledo ${ }^{\circledR}$ hot stage. A film sample with about 60 70 um thickness was prepared by compression molding and sandwiched between two glass plates. Subsequently, the sample was rapidly heated to $280{ }^{\circ} \mathrm{C}$ and kept at this temperature for 10 mins to melt the residual crystals in the sample, and then the sample was rapidly cooled to the desired crystallization temperature to observe isothermal crystallization behavior. The evolution of the morphology of crystalline growth was observed using POM equipped with crossed polarizers after the isothermal crystallization process for $30 \mathrm{~min}$ at $226^{\circ} \mathrm{C}$.

\subsubsection{DSC measurements}

Thermal and crystallization behavior of hybrids with various amounts of Pglass concentrations (up to 15wt\%) were measured by DSC using a TA instrument Q100 in a dry nitrogen atmosphere. The samples were subjected to a heat-cool-heat cycle; heating rate of 10 ${ }^{\circ} \mathrm{C} / \mathrm{min}$ from $30^{\circ} \mathrm{C}$ to $280{ }^{\circ} \mathrm{C}$ with a $5 \mathrm{~min}$ isothermal condition at each selected temperature; and then subsequently cooled to $30^{\circ} \mathrm{C}$ at a rate of $10^{\circ} \mathrm{C} / \mathrm{min}$ followed by reheating at a rate $10{ }^{\circ} \mathrm{C} / \mathrm{min}$ to $280^{\circ} \mathrm{C}$. The peak of the crystallization temperature $\left(T_{p}\right)$ of the sample was obtained. In the case of the isothermal crystallization kinetics experiments, the samples were heated to $280{ }^{\circ} \mathrm{C}$ at a rate of $10{ }^{\circ} \mathrm{C} / \mathrm{min}$ and held at this temperature for $10 \mathrm{~min}$ to remove all previous thermal history, and then followed by rapid cooling to the desired three different crystallization temperatures $\left(T_{c}\right)$ ranging from $204^{\circ}-208{ }^{\circ} \mathrm{C}$ for $20 \mathrm{~min}$ to achieve complete crystallization. Specimens weighing $4.5 \pm 0.4 \mathrm{mg}$ were used to eliminate temperature gradients in the samples.

\subsubsection{Dynamic mechanical analysis (DMA)}

Dynamic mechanical analysis (DMA) was carried out using the TA instrument Q800 following standard procedures operating in the tension mode at a frequency of $1.0 \mathrm{~Hz}$ with a preload of $0.01 \mathrm{~N}$. The temperature was scanned from $0{ }^{\circ} \mathrm{C}$ to $180^{\circ} \mathrm{C}$ with $2{ }^{\circ} \mathrm{C} / \mathrm{min}$ heating rate. The storage (E') and loss (E”) moduli were measured as a function of temperature. The glass transition temperature $\left(\mathrm{T}_{\mathrm{g}}\right)$ of the samples was defined as the temperature at the peak of the loss modulus. 


\subsubsection{Rheological measurements}

Rheological experiments were performed on a MCR501 rheometer (Anton Paar) using a parallel plate geometry with plates of $25 \mathrm{~mm}$ in diameter and a gap of $1 \mathrm{~mm}$. The frequency sweep experiments were performed using a $5 \%$ strain that was previously found to be in the linear viscoelastic region and angular frequency in the range of 0.1 to $100 \mathrm{rad} / \mathrm{s}$. All experiments were done under a dry nitrogen atmosphere to prevent or minimize thermal degradation of the samples.

\subsubsection{Solid state NMR}

${ }^{13} \mathrm{C}$ MAS NMR spectra were obtained on a Bruker Avance III 400 (9.6 T) NMR instrument using a $4 \mathrm{~mm}$ broadband magic-angle spinning (MAS) probe. All spectra were obtained at room temperature and spinning at 10-12 kHz. The cross polarization (CPMAS) NMR spectra were obtained using CP contact time of $3 \mathrm{~ms}$, and a $1 \mathrm{~s}$ recycle delay. The direct polarization (DP) MAS NMR spectra were obtained using a single pulse Bloch decay with a recycle delay of $60 \mathrm{sec}$. The ${ }^{13} \mathrm{C}$ NMR chemical shift was referenced to tetramethylsilane $(\delta)$ using the secondary standard adamantane $\delta=28.5 \mathrm{ppm}$ (most shielded resonance). All spectra deconvolutions were done with DMFIT software Static [23]. ${ }^{1} \mathrm{H}$ and ${ }^{31} \mathrm{P}$ NMR spectra were obtained on a Bruker Avance III 400 (9.6 T) NMR instrument using a $7 \mathrm{~mm}$ broadband DOTY High Temperature Probe in the static mode. 1D NMR spectra were obtained using a Hahn Echo with a $10 \mathrm{~s}$ recycle delay for ${ }^{1} \mathrm{H}$ and a 60 s recycle delay for ${ }^{31} \mathrm{P}$.

\section{Results and discussion}

\subsection{Thermal characteristics}

Fig. 1 shows the non-isothermal crystallization behavior of the control PET and hybrids samples containing three different amounts of Pglass at the cooling rate of $10{ }^{\circ} \mathrm{C} / \mathrm{min}$ from the melting state. The figure indicates a gradual shift of the peak crystallization temperature $\left(T_{p}\right)$ to higher temperatures in the $204.6^{\circ} \mathrm{C}$ to $210.4^{\circ} \mathrm{C}$ temperature range. This observation is attributed to the increasing amount of the Pglass in the hybrids. It is worth noting that the PET polymer composites crystallized at an early stage (i.e., higher temperature) of the cooling process because the dispersed molecular-sized Pglass particles functioned as nucleation agents in the PET matrix hybrids, consistent with previously reported results [24, 25]. In contrast, Liu et al. [26] reported that the value of $T_{p}$ was not significantly influenced by the amount of Pglass in the PET polymer 
matrix hybrids using a $10^{\circ} \mathrm{C} / \mathrm{min}$ of cooling rate. In addition, with a $30{ }^{\circ} \mathrm{C} / \mathrm{min}$ of cooling rate, $\mathrm{T}_{\mathrm{p}}$ was decreased. Compared to previously reported work, this different result in the current study can be attributed to the effective dispersion of Pglass utilizing the melt mixing process already described in the experimental section.

The crystallinity of the Pglass/PET hybrids was further investigated using solid state ${ }^{13} \mathrm{C}$ NMR techniques. The obtained NMR plots are shown in Fig. 2. The crystallinity of the PET composites can be determined from the methylene resonance between $60-70 \mathrm{ppm}$. This peak is associated with the methylene ether segments of the PET polymer [27]. Deconvolution allowed the identification of the overlapping environments at $63 \mathrm{ppm}$ and $66 \mathrm{ppm}$, which correspond to trans and gauche configurations of the aliphatic segment. The integrated intensities allowed the estimation of the crystallinity index of the $10 \mathrm{wt} \%$ Pglass sample with a trans/gauche ratio of 63/37, corresponding to $63 \%$ crystallinity or "ordered" phase in the matrix [27]. This ratio is further reduced to $50 / 50$ in the 50 wt\% Pglass sample. These results clearly show that with increasing Pglass concentrations, the ratio of ordered (or crystalline) phase to less ordered structure is reduced, which is associated with the reduction of overall crystallinity of the hybrid samples. This observation will be further investigated and confirmed in the kinetic study and polarized optical micrographs showing more defective crystals in the hybrid samples.

The thermal stability of the samples is depicted in Fig. 3 showing the TGA curves of the control PET and the PET matrix hybrids incorporating Pglass. There is no significant difference in the onset temperature of thermal degradation between that of the control PET and hybrids at the experimental temperature range tested (i.e., $30^{\circ} \mathrm{C}$ to $600{ }^{\circ} \mathrm{C}$ ). Clearly, the residual amounts of samples after heating to $600{ }^{\circ} \mathrm{C}$ increased as the amount of Pglass was increased in the hybrids due to the addition of inorganic Pglass as a filler, which is a non-decomposable inorganic material.

\subsection{Morphological analysis}

Fig. 4 shows SEM photomicrographs of the cryo-fractured surface of the control PET and Pglass/PET hybrids containing $5 \mathrm{wt} \%$ to $15 \mathrm{wt} \%$ of Pglass. As the amount of Pglass was increased, the size and the number of droplets of Pglass in the PET matrix increased, indicating a phase separation between Pglass and PET in the hybrids. However, EDX analysis showed another interesting result that Pglass was dispersed in nanoscale in the PET matrix. The EDX image in Fig. 5 shows the distribution of phosphorus in the Pglass/PET hybrids, indicating presence of phosphorous not only as discrete micro-size droplets of Pglass but also as droplets 
dispersed in the PET matrix phase. Note that Pglass is distributed at both the microscale and nanoscale in the PET matrix materials. In addition, it is noteworthy that the Pglass droplets prepared by droplet coalescence were encased by PET polymer matrix due to the effective hydrogen bonding interaction between the hydrogen donor in hydroxyl groups from the Pglass and oxygen acceptor atoms in the ester from the PET polymer [20, 26, 28].

As shown in the EDX data of Fig. 5 (c), the PET matrix dominated region (point \#2) showed significant weight percent portion of fluorine $(F)$, phosphorous $(P)$, and tin $(S n)$ elements of the Pglass due to the homogeneous nanoscale dispersion of Pglass in the PET matrix that is ascribed to the low $\mathrm{T}_{\mathrm{g}}$ of Pglass and the physical and chemical compatibility between Pglass and PET matrix materials. These obtained SEM-EDX results are supported by the TEM analysis shown in Fig. 6. This provides a direct evidence of the nano- and micro-scale dispersion of Pglass in the PET polymer matrix via the mixing process in the melt state of the two organic and inorganic components of the hybrid materials studied. The good dispersion of Pglass in the PET matrix is attributed to the formation of hydrogen bonds between the hydrogen and carbonyl group of PET and hydroxyl and fluoride of the Pglass.

The crystalline morphology for the control PET and its hybrids was investigated using polarized optical microscopy (POM) analysis as shown in Fig. 7, which were observed after completion of the isothermal crystallization of samples at the designated crystallization temperature and cooling to the room temperature. As shown in Fig. 7 (a), crystals with a spherulite morphology (Maltese cross pattern) are observed in the control PET samples after isothermal crystallization. In contrast, for the 10 wt\% Pglass/PET hybrid (see Fig. 7 (b)), a relatively large number of discrete crystals were observed due to the heterogeneous nucleation sites (Pglass particle surface) and subsequent impingement of crystals during the growth process attributed to the close distance between the crystals. It is worth noting that the addition of Pglass increased the heterogeneity of the polymer crystal growth in the hybrids causing a nucleating effect of Pglass molecules in the hybrids as already described. This last observation is consistent with the result of the shift of the peak of crystallization temperature in the cooling process already mentioned. In addition, it was observed that the increased heterogeneous nucleation obstructed the crystal growth, resulting in the observed decrease of overall crystallinity of PET polymer in the hybrids as already discussed.

3.3. Nucleation effect of Pglass in isothermal melt crystallization 
Fig. 8 (a) shows the plot of relative crystallinity $X(t)$ versus crystallization time $(\mathrm{min})$ for the isothermal crystallization of the control PET and its hybrids. The relative crystallinity at time $t, X(t)$ is defined as shown in Eq. (1) [29, 30].

$$
X(t)=\frac{X_{c}(t)}{X_{c}\left(t_{\infty}\right)}=\frac{\int_{0}^{t} \frac{d H_{c}(t)}{d t} d t}{\int_{0}^{t_{\infty}} \frac{d H_{c}(t)}{d t} d t}
$$

where $H_{c}(t)$ is the crystallization enthalpy at time $t$ and $d H_{c}(t) / \mathrm{d} t$ is the rate of heat evolution. Fig. 8 (a) shows that the characteristic sigmoidal isotherms are shifted to the left with increasing amount of Pglass in the hybrids, indicating a faster crystallization rate caused by the addition of Pglass. Another critical parameter is the half-time of crystallization $\left(\mathrm{t}_{1 / 2}\right)$ indicating the time at which $X(t)$ is $50 \%$ and $G$ is defined as the reciprocal of $t_{1 / 2}$ which represents the crystallization rate [31]. The $t_{1 / 2}$ can be directly derived from experimental $X(t)$ data or calculated using the following equation [32]:

$$
t_{1 / 2}=\left(\frac{\ln 2}{K}\right)^{1 / n}
$$

where $n$ is Avrami constant and $K$ is crystallization rate constant. To obtain the maximum crystallization, the following equation can be applied as reported by Lin [33].

$$
t_{\max }=\left(\frac{n-1}{n K}\right)^{1 / n}
$$

The half-time of crystallization ( $\left.t_{1 / 2}\right)$, the reciprocal of $t_{1 / 2}$ (i.e., $G$ parameter) indicating crystallization rate, and the time for maximum crystallization, $t_{\max }$, are summarized in Table 1 . The Table shows that $t_{1 / 2}$ of Pglass/PET hybrids decreased from 1.170 to 0.677 as the amount of Pglass increased from $0 \mathrm{wt} \%$ to $15 \mathrm{wt} \%$, indicating that the crystallization rate $(\mathrm{G})$ increased and the time for maximum crystallization $\left(t_{\max }\right)$ decreased. This observed increase of crystallization rate in isothermal crystallization is consistent with the results of Pglass/PP hybrid system reported by Guschl et al. [19] and of clay/PET hybrid system reported by Wan et al. [16].

The characteristic sigmoidal isotherms were shifted to the right with increasing crystallization temperatures $\left(T_{c}\right)$ as depicted in Fig. $9(a)$ and (b), indicating that the crystallization rate becomes slower for both the control PET and the Pglass/PET hybrids. Using these relative 
crystallization data, an Avrami analysis was carried out to investigate the isothermal crystallization kinetics for the samples. The general form of Avrami equation [34-36] is

$$
\mathrm{X}(\mathrm{t})=1-\exp \left(-K t^{n}\right)
$$

where $n$ is a Avrami constant which is related to dimensional features of crystal nucleation and growth and $K$ is the crystallization rate constant related to nucleation and growth rate of crystal in crystallization process. Eq. (4) can be written in another form after taking logarithm two times as follows:

$$
\log \{-\ln (1-\mathrm{X}(\mathrm{t}))\}=n \log t+\log K
$$

Using the logarithm form of Avrami equation, Eq. (5), the plots of $\log \{-\ln (1-\mathrm{X}(\mathrm{t}))\}$ versus $\log$ $t$ was obtained (see Fig. 10). The Avrami constant $(n)$ and crystallization rate constant $(K)$ were obtained from the slope and intercept of the straight line, respectively, by fitting the data using the Avrami model. Rahimi et al. [29] separated the overall crystallizations into three sections consisting of initial stage (nucleation), linear stage (growth of crystallization), and final stage (impingement of crystallization) to focus on the growth stage on the linear portion of Avrami plot. In the current study, the linear stage was determined to be between $5 \%$ and $70 \%$ of relative degree of crystallization and the Avrami graph was plotted using the linear range shown earlier in Fig. 8 (b).

The obtained kinetic parameter data from the Avrami model analysis is summarized in Table 1 for the isothermal crystallization of the Pglass/PET hybrids incorporating various Pglass concentration. As proposed by Bian et al. [37], the Avrami constant, $n$, is related to the number of growth points in crystal nuclei. Typically, $n$ values of the 2D lamellar crystals are 2 or 3 , and the 3D spherulite crystals are 3 or 4 . A schematic diagram of the evolution of the spherulite crystal of PET was reported by Lee et al. [38], showing that 3D spherulites are formed by the growth of branches of 2D lamellae. In the current study, the $n$ values were found to be about 3 or 4 , indicating formation of 3D spherulite crystals during the PET crystallization process. The kinetic parameters obtained from the Avrami analysis of the data shown in Fig. 10 for the isothermal crystallization of the control PET and $15 \mathrm{wt} \%$ Pglass/PET hybrids at three different isothermal crystallization temperatures are listed in Table 2. Interestingly, the $n$ value of control PET is larger than that of its hybrids, indicating that incorporation of Pglass reduces the dimensions of the PET crystals. In other words, the presence of Pglass particles in the PET matrix results in development 
of less perfect spherulitic crystals. As shown earlier in Fig. 7, it is worth noting that there are more nucleation sites produced by Pglass molecules in the hybrids compared to that of the control PET which is responsible for the observed increase of the crystallization sites and the associated decrease of the crystal dimensions in the hybrids, as other researchers have previously reported for similar systems $[14,18,39]$. As shown in Tables 1 and 2 the values of $K$ and $G$ corresponding to the crystallization growth rates significantly increased due to the decrease of the values of maximum crystallization time ( $\left.t_{\max }\right)$ and the half-time of crystallization $\left.\left(t_{1 / 2}\right)\right)$ as the amount of Pglass was increased. This indicates that nano- and micro-scale dispersed Pglass particles in the hybrids effectively functioned as the polymer crystal nucleation agents. In addition, the crystallization rate (i.e. $K$ ) decreased as the crystallization temperature $\left(T_{c}\right)$ increased from $204^{\circ} \mathrm{C}$ to $208^{\circ} \mathrm{C}$ both for the control PET and $15 \mathrm{wt} \%$ Pglass/PET hybrid. Clearly, this is due to the relatively slower exothermal heat transfer during the crystallization at the higher temperature, resulting in the observed increase of maximum crystallization time $\left(t_{\max }\right)$ and the half-time of crystallization $\left(\mathrm{t}_{1 / 2}\right)$ shown in Table 2 .

\subsection{Mechanical properties}

Dynamic mechanical analysis was carried out on the materials to investigate their mechanical properties such as storage ( $\left.E^{\prime}\right)$ and loss ( $\left.E^{\prime \prime}\right)$ which respectively indicates the energy stored as elastic energy and the energy dissipated due to the friction of polymer chain movement. Fig. 11 (a) shows the variation of E' versus temperature for the control PET and its hybrids. The E' increased with increasing Pglass content up to $15 \mathrm{wt} \%$, indicating the stiffening effect of the inorganic Pglass molecules in the PET polymer matrix. In addition, the increase of E' was relatively higher at temperatures below the $T_{g}$ compared to that observed at higher temperatures in agreement with the previously reported results in the literature [20]. The E" plotted as a function of temperature is shown in Fig. 11 (b). This graph shows that the glass transition temperature $\left(T_{g}\right)$ defined as the maximum value of loss modulus slightly shifted to the left (i.e. decrease of $T_{g}$ ) due to the addition of Pglass. This shows that the Pglass functioned as a plasticizer in the Pglass/PET hybrids. This observed decrease of $T_{g}$ is consistent with the previously reported work by Urman et al [6] on polyamide matrix containing a Pglass filler, where the authors report that the plasticizing effect is caused by higher mobility of polymer chains at the interfacial areas between the filler and matrix material in the hybrids $[40,41]$ due to the smooth surface of Pglass particles. 


\subsection{Rheological properties}

The rheological properties of the Pglass/PET hybrids were studied using dynamic small amplitude oscillatory shear rheology to assess the effect of microstructure development and the potential effects of the interactions at the PET-Pglass interfacial area on melt rheological properties. The variation of the complex viscosity versus angular frequency is shown in Fig. 12 (a-c) for the pure PET, Pglass and the hybrids at different temperatures of $255^{\circ} \mathrm{C}, 265{ }^{\circ} \mathrm{C}$ and $280{ }^{\circ} \mathrm{C}$, respectively. This figure shows that the pure Pglass exhibits a Newtonian behavior at all three temperatures studied [21]. This last observation is ascribed to the relatively small size of inorganic Pglass chain segments. The pure PET matrix shows a Newtonian behavior with slight shear thinning at very high frequencies especially at the lowest temperature (i.e, $255^{\circ} \mathrm{C}$ ). Interestingly, with the addition of the Pglass, the viscosity of the hybrids dropped to lower values compared to that of the neat PET and Pglass. As can be seen in Fig. 12, with the addition of the 5 wt\% Pglass to PET, the sample showed relatively lower dynamic viscosity values throughout the whole range of frequencies studied compared to that of neat components (i.e., PET and Pglass). With increasing Pglass content, a further decrease in the viscosity values for $10 \mathrm{wt} \%$ and 30 wt\% of Pglass hybrids was observed. Note that the observed viscosity reduction of polymers with addition of Pglass is similar to our previously reported systems of polyamide and Pglass [21]. There are a number of possible reasons for such observation. First, it is believed that the Pglass could potentially impose an interfacial lubrication effect due to the low molecular weight and oligomeric nature of Pglass chains causing the PET chains to slide pass each other. Second, the presence of Pglass could disrupt the chain entanglement in the PET matrix which consequently promotes the viscous flow of the hybrid melt. This non-Einstein-like decrease of viscosity in polymer melts due to the presence of nanoparticulate inclusions has been previously reported in the literature by a number of researchers $[42,43]$. In addition, the strong interaction of Pglass with PET through hydrogen bonding can disrupt the inter- and intra-molecular hydrogen bonding of the PET chains, resulting in observed viscosity changes.

Here, we also speculate that Pglass may disrupt (depolymerize) the PET chains through transesterification of the ester bond via the nucleophilic attacks of the anionic form of the phosphate groups $\left(\mathrm{PO}_{4}{ }^{3-}\right)$ which reduces the molecular weight the PET and subsequently reduces the melt viscosity. This hypothesis is currently under further investigation and will be reported elsewhere. Note that the current Pglass/PET hybrids show a different behavior at the terminal zone of the dynamic shear flow compared to that of the pure components. The results show that, while the hybrid sample with $5 \%$ Pglass exhibits a similar behavior to that of pure PET matrix, as 
the Pglass content is increased, there appears to be a sharp increase in the complex viscosity in the terminal zone of the frequencies (i.e., low frequency region). This sharp increase in viscosity in the low frequency range is clearly observed in the $10 \mathrm{wt} \%$ Pglass/PET hybrid sample. However, this observed viscosity increase is most significant in the $30 \mathrm{wt} \%$ Pglass/PET hybrid. The evolution of such non-terminality of complex viscosity is associated with the development of an elastic structure and yield stress behavior [44-46].

In order to further elaborate on this observation, the variation of storage modulus ( $G$ ') of the samples at all three different temperatures is shown in Fig. 13 (a-c). First, it is shown that the $\mathrm{G}^{\prime}$ of the hybrids is lower than that of the pure component at $255^{\circ} \mathrm{C}$ which is consistent with the lubrication effect as already described. Second, as the Pglass content is increased in the hybrids from 5 to $30 \%$, the G' increased (relative to that of the hybrids) due to the presence of the Pglass component. More importantly, the non-terminal behavior of the hybrids is evident in the reduction of the slope of the terminal zone of the G'. As shown in Fig. 13, with increasing Pglass content and increasing temperatures, the slope of the G' at low frequency values reduces. For example, while the slope of the terminal zone of the G' for samples with 5, 10 and $30 \%$ Pglass are respectively $1.26,1.11$ and 0.89 at $255^{\circ} \mathrm{C}$; they change to $0.94,0.78$ and 0.42 at a temperature of $280{ }^{\circ} \mathrm{C}$. This evolution of nonterminal behavior is associated with structural changes in the Pglass/polymer hybrid where certain elastic contributions prolong the structural relaxation in the low frequency regions. Typically, in nanoparticle filled systems, this reduction of slope is associated with formation of elastic filler network, while in the current hybrid system, it is likely that Pglass (that is liquid in this temperature condition) undergoes a structural reorganization (formation of an intermediate range structures) that imparts such longer melt relaxation to the hybrid.

The effects of composition and temperature on the compatibility of the hybrids components can be further studied using the log G' vs log G", modified Cole-Cole plots (or Han plots) which have been used in a number of previous studies on various polymer blend systems [47]. The Han plots of neat PET and the Pglass/PET hybrids are shown in Fig. 14 (a-d) at three different temperatures of $255^{\circ} \mathrm{C}, 265^{\circ} \mathrm{C}$ and $280{ }^{\circ} \mathrm{C}$. As can be seen in this figure, for the neat PET, there is a temperature independence for log G' vs log G”. Interestingly, as the Pglass content is increased in the system from 5 to $30 \%$, the temperature independence of the Han plot is broken down. For the $5 \%$ Pglass, this deviation is relatively less compared to that observed at higher concentrations, showing good compatibility between the hybrid components and microstructure, indicating less influence by the temperature. As the Pglass content is increased, especially for 
$30 \%$ hybrid, there is a larger deviation of the Cole-Cole diagram from temperature independence. This deviation is associated with a microstructure that is dependent on the temperature. It is evident that with increasing Pglass content in the hybrids, the samples become rheologically complex fluids with clear dependency on the temperature. In fact, it is believed that with increasing temperature, the interfacial interactions between the PET and Pglass are strengthened, which can improve the miscibility of the components. Such improvement of the interactions and interfacial miscibility could be a contributing factor in the earlier observation that with increasing the temperature, the nonterminality of the plots of $\eta^{*}$ and $G^{\prime}$ versus frequency was promoted especially as the Pglass content was increased in the blend.

3.6. Variable-temperature (VT) ${ }^{31} \mathrm{P}$ and ${ }^{1} \mathrm{H}$ solid state NMR.

The static variable-temperature (VT) ${ }^{31} \mathrm{P}$ NMR for pure Pglass and two hybrids is shown in Fig. 15. The local chain fluctuations of materials will produce signal narrowing with increasing amounts of motion attributed to increased temperature $[48,49]$ until the molecules undergo isotropic dynamics like a liquid. It is obvious that pure Pglass melts at higher temperature to produce two sharp resonances as shown in Fig. 15(a) different from that of the other two hybrids, showing broad peaks at high temperature. This result indicates that Pglass in the hybrids did not undergo a melting transition in this temperature range, but it showed a very minor reduction in linewidth with increasing temperature due to the addition of Pglass causing interfacial interaction between PET and Pglass molecules.

In addition, Fig. 16 elucidates that average ${ }^{31} \mathrm{P}$ linewidths of $50 \mathrm{wt} \%$ Pglass sample are narrower than that of $10 \mathrm{wt} \%$ Pglass sample as the temperature increased, indicating that Pglass molecules in $50 \mathrm{wt} \%$ Pglass sample has more dynamic than that of $10 \mathrm{wt} \%$ Pglass. This result shows that with increasing Pglass content from $10 \mathrm{wt} \%$ to $50 \mathrm{wt} \%$, the compatibility of the PET and Pglass phases is reduced (i.e., the sample with lower Pglass showed relatively stronger interfacial interactions at the interface of Pglass droplets and PET matrix phase that restricts the molecular mobility of the hybrid components). At high Pglass concentrations, the PET and Pglass phases become increasingly less compatible, generating more unfavorable interactions and associated increased molecular mobility. This observation is consistent with the SEM images showing relatively larger Pglass droplets as the glass content was increased in the hybrids. These larger droplets provide less interfacial area for PET-Pglass interactions and consequently, the apparent chain dynamics of the system increases as evidenced in the VT NMR results. It is very 
interesting to note that pure Pglass showed significantly increased mobility at higher temperatures while the nano- and micro-sized Pglass particles dispersed in the PET matrix showed only a slight increase of motion with increasing temperatures. This last result is attributed to the nano- and micro-scale interfacial interactions between Pglass and PET molecules.

Further, the obtained VT ${ }^{1} \mathrm{H}$ NMR $[48,50]$ results are depicted in Fig. 17. In this figure, the pure PET showed a relatively larger linewidth at lower temperature, reflecting higher rigidity (due to higher crystallinity) in the pure PET compared to that of the PET phase in the hybrids. Increasing temperatures near the melting point of PET, the pure PET showed slightly smaller linewidth compared to that of the hybrids, implying that the mobility of the PET polymer chains near the Pglass molecules in the hybrids is restricted by the Pglass molecules. It is worth noting that the average ${ }^{1} \mathrm{H}$ rigid linewidth of the PET decreased slightly (i.e., increased chain mobility) with increasing Pglass content from $10 \mathrm{wt} \%$ to $50 \mathrm{wt} \%$ due to the reduced compatibility and less favorable interfacial interactions at higher Pglass concentrations together with the change in the morphology of the hybrids and formation of the larger Pglass droplets (i.e., less interfacial area) in the PET matrix.

\section{Conclusions}

In this study, PET matrix hybrid incorporated with polydispersed ultra low $\mathrm{T}_{\mathrm{g}}$ Pglass was characterized by a number of characterizations and analysis methods to study the physical properties of hybrids. The morphology of the fracture surface of samples was investigated by the SEM. In addition, the dispersion of Pglass molecules in the PET matrix was observed by EDX, which showed that Pglass was polydispersed in the PET matrix hybrids. These results were confirmed by TEM analysis showing various sizes of Pglass particles from nano- to micro-meter in the polymer matrix. In addition, the results showed that the nanoscale and microscale dispersed Pglass in the hybrid materials functioned as a nucleation agent based on the results that the peak of crystallization temperature shifted to a higher temperature with increasing concentrations of Pglass in the PET matrix during the non-isothermal crystallization at $10{ }^{\circ} \mathrm{C} / \mathrm{min}$ cooling rate. In the isothermal crystallization process, Avrami analysis showed that $\mathrm{K}$ (the crystallization rate constant) and $G$ (the reciprocal of $t_{1 / 2}$ ) values increased as the amount of Pglass was increased in the hybrids materials at the given specific isothermal crystallization temperature, indicating that the addition of Pglass molecules in the hybrids enhanced nucleation process and crystal growth rate. 
In contrast, crystallinity of the hybrids was reduced as the amount of Pglass increased due to the defective crystals prepared by heterogeneous nucleation of the Pglass particles.

The addition of inorganic Pglass in the PET matrix caused the observed increase of the storage modulus due to the stiffening effect of inorganic filler in the polymer matrix. It was also observed that Pglass functioned as a plasticizer in the hybrids. The glass transition temperature was shifted to the left (i.e. decrease of $T_{g}$ ) in the reported loss modulus data, indicating that Pglass functioned as a plasticizer, which would be caused by higher mobility of polymer chains at the interfacial areas between the filler and matrix material in the hybrids. Overall, it can be concluded from the results of this study that Pglass molecules showed crystal nucleation activity as well as plasticizing effect in the PET polymer matrix. This latter remarkable lubrication effect is consistent with the obtained results of rheological properties of hybrids, indicating that the viscosity was decreased as Pglass content in the hybrids increased. In addition, the observed development of nonterminal behavior and the temperature dependence on the rheological properties with increasing the Pglass content and temperature indicate that the Pglass induces rheological complexity to the hybrid systems. Further, the variable temperature NMR results showed a concentration-dependent interfacial interaction between the Pglass and PET. These remarkable special properties of Pglass in the polymer matrix hybrids will provide useful information for a better understanding of the fundamental physical properties of Pglass/polymer hybrids for a number of application areas where traditional polymer composites are not useable.

\section{Acknowledgements}

This work was supported by the U.S. National Science Foundation of Division of Materials Research through DMR-1360006. We thank Jessica Douglas (TEM) and Dr Broadhead (DSC) for their technical assistance in data acquisition. The NMR portion of this work (T.M.A. and E.G.S) was performed at Sandia National Laboratories which is a multi-mission laboratory managed and operated by National Technology and Engineering Solutions of Sandia, LLC., a wholly owned subsidiary of Honeywell International, Inc., for the U.S. Department of Energy's National Nuclear Security Administration under contract DE-NA-0003525. The views expressed in the article do not necessarily represent the views of the U.S. Department of Energy or the United States Government. 


\section{References}

1. Gao, F., Clay/polymer composites: the story. Materials today, 2004. 7(11): p. 50-55.

2. Ray, S.S. and M. Okamoto, Polymer/layered silicate nanocomposites: a review from preparation to processing. Progress in polymer science, 2003. 28(11): p. 1539-1641.

3. Han, Z. and A. Fina, Thermal conductivity of carbon nanotubes and their polymer nanocomposites: a review. Progress in polymer science, 2011. 36(7): p. 914-944.

4. Nandan, B., L. Kandpal, and G. Mathur, Poly (ether ether ketone)/poly (aryl ether sulfone) blends: melt rheological behavior. Journal of Polymer Science Part B: Polymer Physics, 2004. 42(8): p. 1548-1563.

5. Tucker III, C.L. and P. Moldenaers, Microstructural evolution in polymer blends. Annual Review of Fluid Mechanics, 2002. 34(1): p. 177-210.

6. Urman, K. and J.U. Otaigbe, New phosphate glass/polymer hybrids-Current status and future prospects. Progress in Polymer Science, 2007. 32(12): p. 1462-1498.

7. Arkles, B., Commercial applications of sol-gel-derived hybrid materials. MRS bulletin, 2001. 26(5): p. 402-408.

8. Loy, D.A., Hybrid organic-inorganic materials. MRS Bulletin, 2001. 26(5): p. 364-367.

9. Reinsch, V.E. and L. Rebenfeld, Crystallization processes in poly (ethylene terephthalate) as modified by polymer additives and fiber reinforcement. Journal of applied polymer science, 1994. 52(5): p. 649-662.

10. Anand, K.A., U. Agarwal, and R. Joseph, Carbon nanotubes induced crystallization of poly (ethylene terephthalate). Polymer, 2006. 47(11): p. 3976-3980.

11. Gao, Y., et al., Functionalized multi-walled carbon nanotubes improve nonisothermal crystallization of poly (ethylene terephthalate). Polymer Testing, 2008. 27(2): p. 179-188.

12. Wang, Y., et al., Study on mechanical properties, thermal stability and crystallization behavior of PET/MMT nanocomposites. Composites part B: engineering, 2006. 37(6): p. 399-407.

13. Jiang, X., et al., Effect of nucleating agents on crystallization kinetics of PET. Express Polym Lett, 2007. 1(4): p. 245-251.

14. Run, M., et al., Melting behaviors and isothermal crystallization kinetics of poly (ethylene terephthalate)/mesoporous molecular sieve composite. Polymer, 2005. 46(14): p. 5308-5316.

15. Yoo, H.J., et al., Effects of carbon nanotube functionalization and annealing on crystallization and mechanical properties of melt-spun carbon nanotubes/poly (ethylene terephthalate) fibers. Composites Science and Technology, 2012. 72(15): p. 1834-1840.

16. Wan, T., et al., Crystalline morphology and isothermal crystallization kinetics of poly (ethylene terephthalate)/clay nanocomposites. Journal of Applied Polymer Science, 2004. 94(4): p. 13811388.

17. Wang, Y., et al., Nonisothermal melt crystallization kinetics of poly (ethylene terephthalate)/clay nanocomposites. Journal of applied polymer science, 2004. 91(1): p. 308-314.

18. Ke, Y.-C., T.-B. Wu, and Y.-F. Xia, The nucleation, crystallization and dispersion behavior of PETmonodisperse SiO2 composites. Polymer, 2007. 48(11): p. 3324-3336.

19. Guschl, P.C. and J.U. Otaigbe, Crystallization kinetics of low-density polyethylene and polypropylene melt-blended with a low-Tg tin-based phosphate glass. Journal of applied polymer science, 2003. 90(12): p. 3445-3456.

20. Urman, K. and J. Otaigbe, Novel phosphate glass/polyamide 6 hybrids: miscibility, crystallization kinetics, and mechanical properties. Journal of Polymer Science Part B: Polymer Physics, 2006. 44(2): p. 441-450.

21. Urman, K., T. Schweizer, and J.U. Otaigbe, Rheology of tin fluorophosphate glass/polyamide 12 hybrids in the low concentration regime. Journal of rheology, 2007. 51(6): p. 1171-1187. 
22. Adalja, S.B. and J.U. Otaigbe, Melt rheology of tin phosphate glasses. Appl Rheol, 2001. 11(1): p. 10-18.

23. Massiot, D., et al., Modelling one-and two-dimensional solid-state NMR spectra. Magnetic resonance in chemistry, 2002. 40(1): p. 70-76.

24. Chae, D.W. and B.C. Kim, Thermal and rheological properties of highly concentrated PET composites with ferrite nanoparticles. Composites science and technology, 2007. 67(7): p. 13481352.

25. Ke, Y.-C., T.-B. Wu, and Y.-F. Xia, The nucleation, crystallization and dispersion behavior of PETmonodisperse SiO 2 composites. Polymer, 2007. 48(11): p. 3324-3336.

26. Liu, H., et al., The effect of Pglass state on the non-isothermal cold and melt crystallization processes of PET matrix. Thermochimica Acta, 2015. 613: p. 1-8.

27. Huang, J.-M., P. Chu, and F.-C. Chang, Conformational changes and molecular motion of poly (ethylene terephthalate) annealed above glass transition temperature. Polymer, 2000. 41(5): p. 1741-1748.

28. Lommerse, J.P., S.L. Price, and R. Taylor, Hydrogen bonding of carbonyl, ether, and ester oxygen atoms with alkanol hydroxyl groups. Journal of computational chemistry, 1997. 18(6): p. 757774.

29. Rahimi, S.K. and J.U. Otaigbe, The role of particle surface functionality and microstructure development in isothermal and non-isothermal crystallization behavior of polyamide 6/cellulose nanocrystals nanocomposites. Polymer, 2016. 107: p. 316-331.

30. Chiu, F.-C., Y. Peng, and Q. Fu, Bulk crystallization kinetics of metallocene polyethylenes with well-controlled molecular weight and short chain branch content. Journal of Polymer Research, 2002. 9(3): p. 175-181.

31. Knauer, K.M., et al., Rheological and crystallization enhancement in polyphenylenesulfide and polyetheretherketone POSS nanocomposites. Journal of Applied Polymer Science, 2017. 134(7).

32. Chen, X., C. Li, and W. Shao, Isothermal crystallization kinetics and melting behaviour of PET/ATO nanocomposites prepared by in situ polymerization. European polymer journal, 2007. 43(8): $\mathrm{p}$. 3177-3186.

33. Lin, C., The rate of crystallization of poly (ethylene terephthalate) by differential scanning calorimetry. Polymer Engineering \& Science, 1983. 23(3): p. 113-116.

34. Avrami, M., Kinetics of phase change. I General theory. The Journal of Chemical Physics, 1939. 7(12): p. 1103-1112.

35. Avrami, M., Granulation, phase change, and microstructure kinetics of phase change. III. The Journal of chemical physics, 1941. 9(2): p. 177-184.

36. Avrami, M., Kinetics of phase change. II transformation-time relations for random distribution of nuclei. The Journal of Chemical Physics, 1940. 8(2): p. 212-224.

37. Bian, J., S.R. Ye, and L.X. Feng, Heterogeneous nucleation on the crystallization poly (ethylene terephthalate). Journal of Polymer Science Part B: Polymer Physics, 2003. 41(18): p. 2135-2144.

38. Lee, C.H., H. Saito, and T. Inoue, Time-resolved light scattering studies on the early stage of crystallization in poly (ethylene terephthalate). Macromolecules, 1993. 26(24): p. 6566-6569.

39. Canetti, M. and F. Bertini, Supermolecular structure and thermal properties of poly(ethylene terephthalate)/lignin composites. Composites Science and Technology, 2007. 67(15-16): p. 3151-3157.

40. Ash, B.J., R.W. Siegel, and L.S. Schadler, Glass-transition temperature behavior of alumina/PMMA nanocomposites. Journal of Polymer Science Part B: Polymer Physics, 2004. 42(23): p. 4371-4383.

41. Sun, Y., et al., Glass transition and relaxation behavior of epoxy nanocomposites. Journal of Polymer Science Part B: Polymer Physics, 2004. 42(21): p. 3849-3858. 
42. Mackay, M.E., et al., Nanoscale effects leading to non-Einstein-like decrease in viscosity. Nature materials, 2003. 2(11): p. 762-766.

43. Tuteja, A., et al., Effect of ideal, organic nanoparticles on the flow properties of linear polymers: non-Einstein-like behavior. Macromolecules, 2005. 38(19): p. 8000-8011.

44. Hoffmann, B., et al., Rheology of nanocomposites based on layered silicates and polyamide-12. Colloid \& Polymer Science, 2000. 278(7): p. 629-636.

45. Jafari, S., et al., Multicomponent blends based on polyamide 6 and styrenic polymers: morphology and melt rheology. Polymer, 2002. 43(25): p. 6985-6992.

46. Rahimi, S.K. and J.U. Otaigbe, The effects of the interface on microstructure and rheo-mechanical properties of polyamide 6/cellulose nanocrystal nanocomposites prepared by in-situ ringopening polymerization and subsequent melt extrusion. Polymer, 2017. 127: p. 269-285.

47. Han, C.D. and H.K. Chuang, Criteria for rheological compatibility of polymer blends. Journal of applied polymer science, 1985. 30(11): p. 4431-4454.

48. Goward, G.R., et al., High-resolution solid-state NMR studies of imidazole-based proton conductors: Structure motifs and chemical exchange from $1 H$ NMR. The Journal of Physical Chemistry B, 2002. 106(36): p. 9322-9334.

49. Kapur, G., et al., Studies on competitive interactions and blending order of engine oil additives by variable temperature 31P-NMR and IR spectroscopy. Tribology transactions, 1999. 42(4): p. 807812.

50. Apperley, D.C., et al., Characterisation of indomethacin and nifedipine using variabletemperature solid-state NMR. Magnetic Resonance in Chemistry, 2005. 43(11): p. 881-892. 
Figures

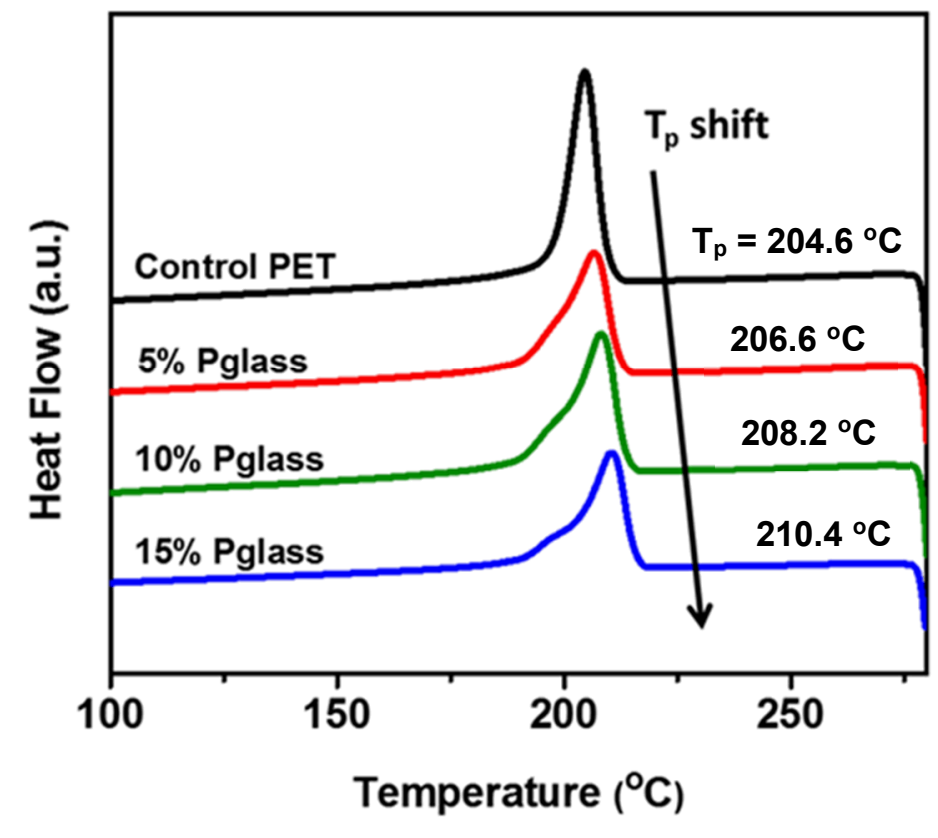

Fig. 1. The DSC thermograms of the peaks of the crystallization temperature $\left(T_{p}\right)$ in the PET matrix hybrids incorporating $0-15 \mathrm{wt} \%$ Pglass. 


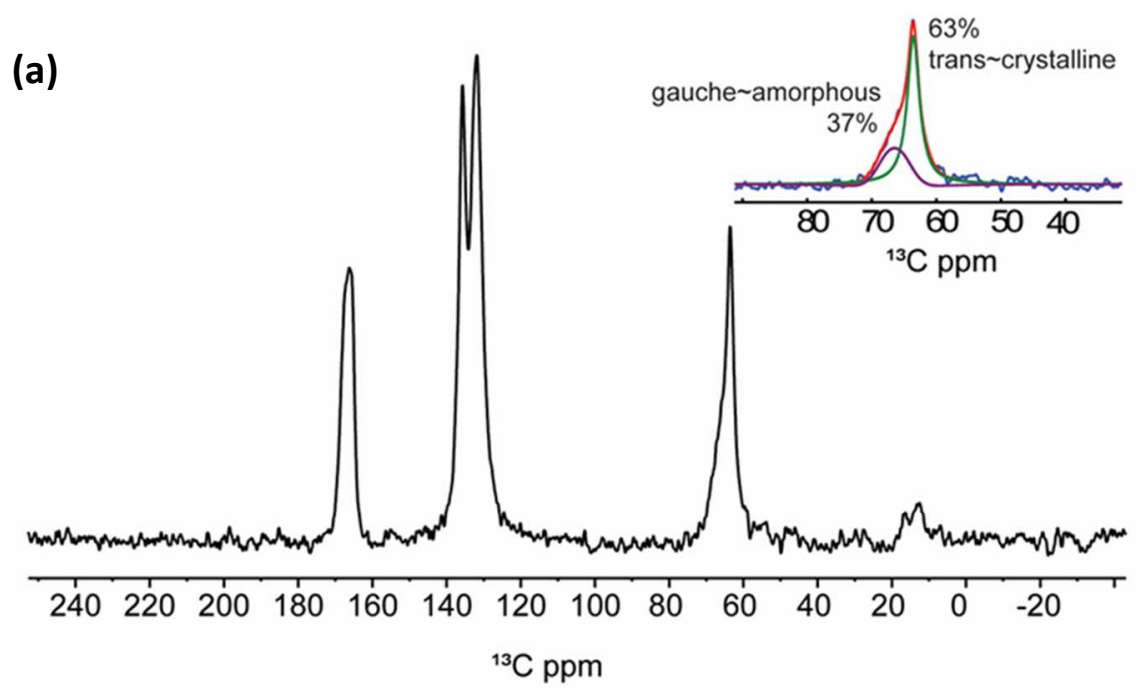

(b)

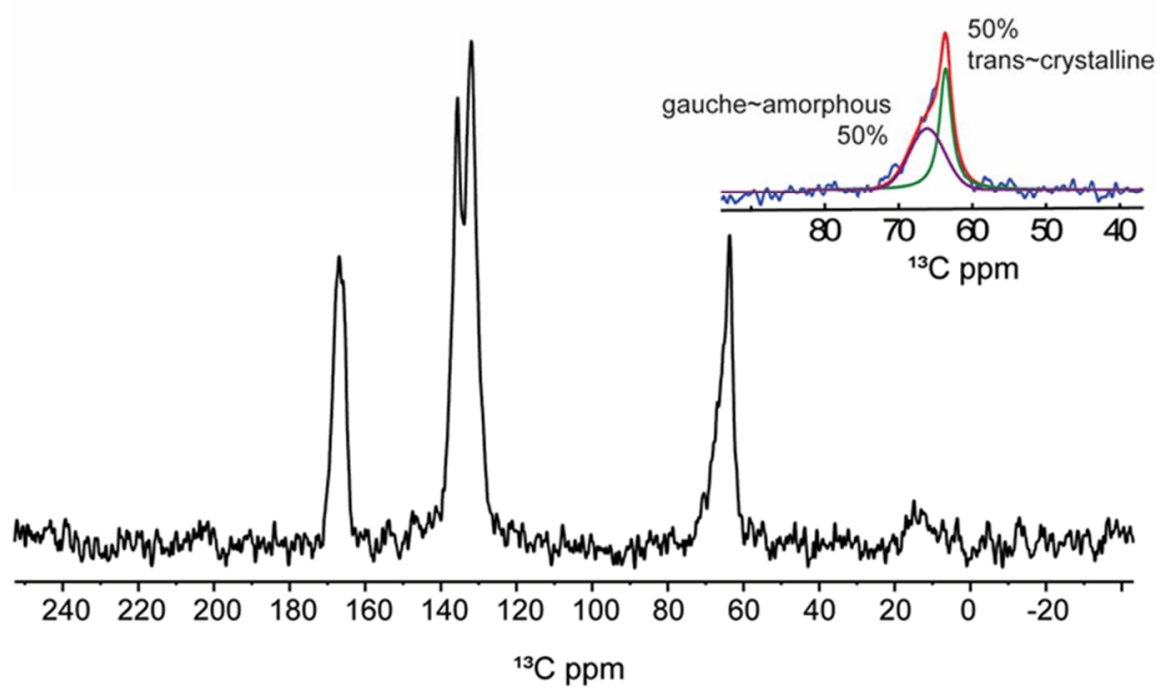

Fig. 2. ${ }^{13} \mathrm{C}$ DPMAS solid-state NMR spectra. (a) $10 \mathrm{wt} \%$ Pglass composite and (b) $50 \mathrm{wt} \%$ Pglass hybrids. Spectra were fitted for methylene resonance using Gaussian/Lorentzian functions. 


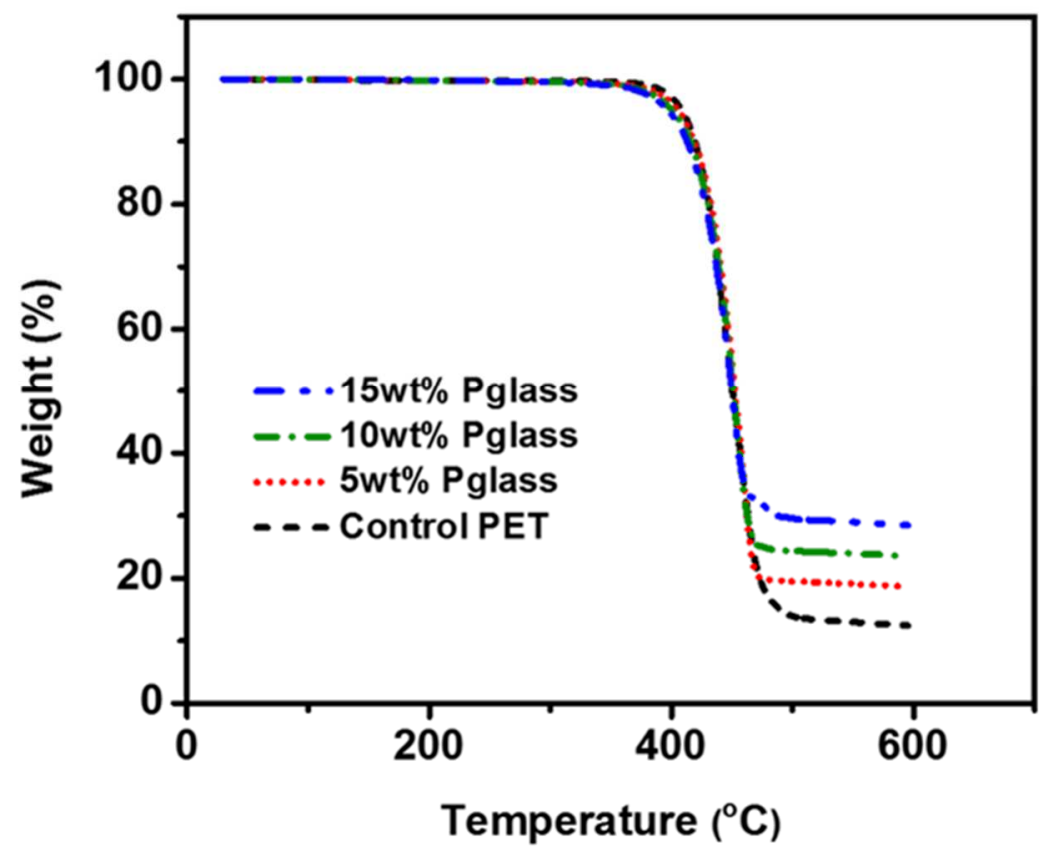

Fig. 3. TGA curves for the control PET and its hybrids incorporating Pglass concentrations indicated, recorded at $10^{\circ} \mathrm{C} / \mathrm{min}$ in nitrogen gas atmosphere. 

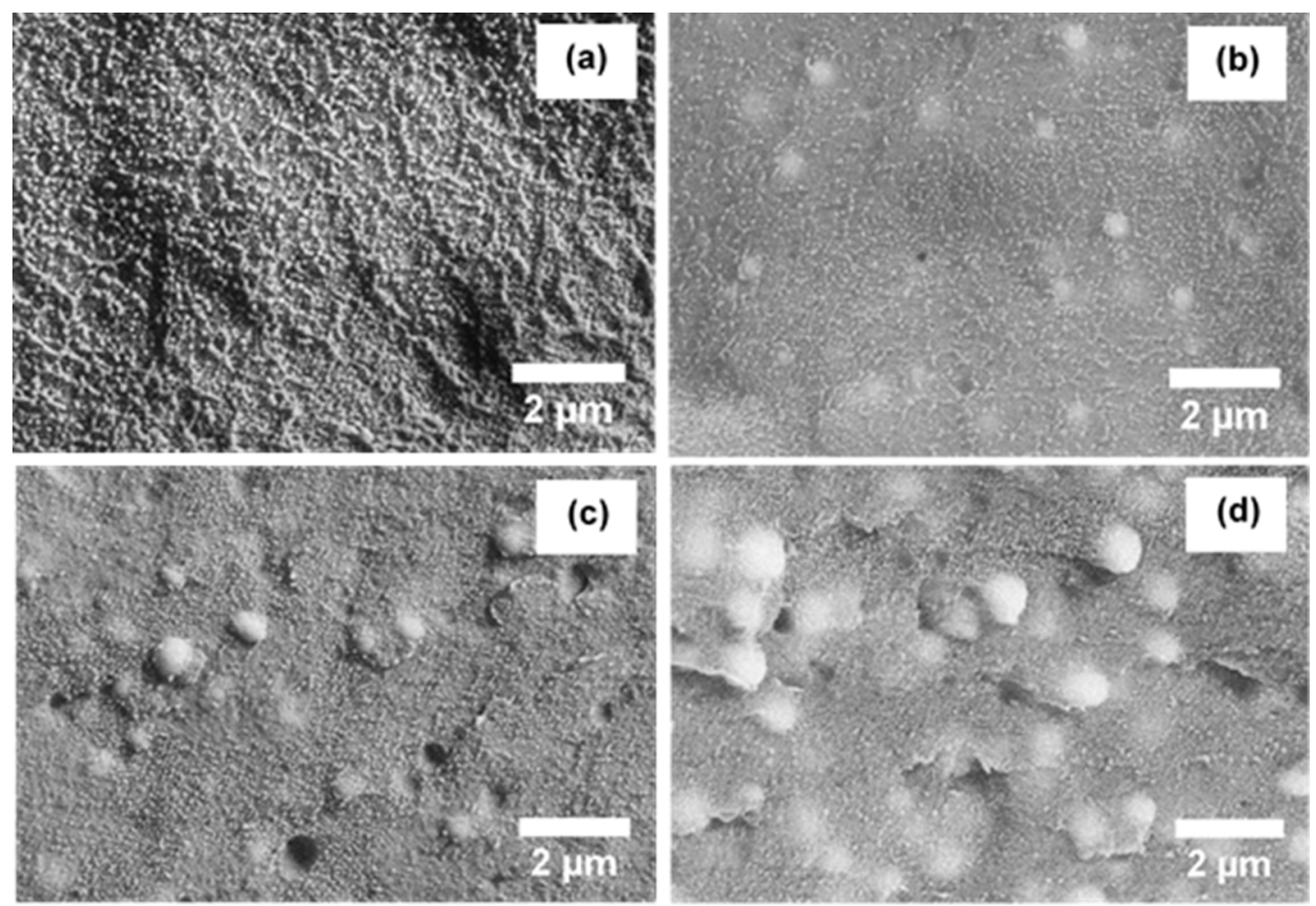

Fig. 4. SEM images of fracture surface of (a) the control PET and PET matrix hybrids incorporating (b) $5 \mathrm{wt} \%$, (c) $10 \mathrm{wt} . \%$, and (d) $15 \mathrm{wt} \%$ Pglass. 

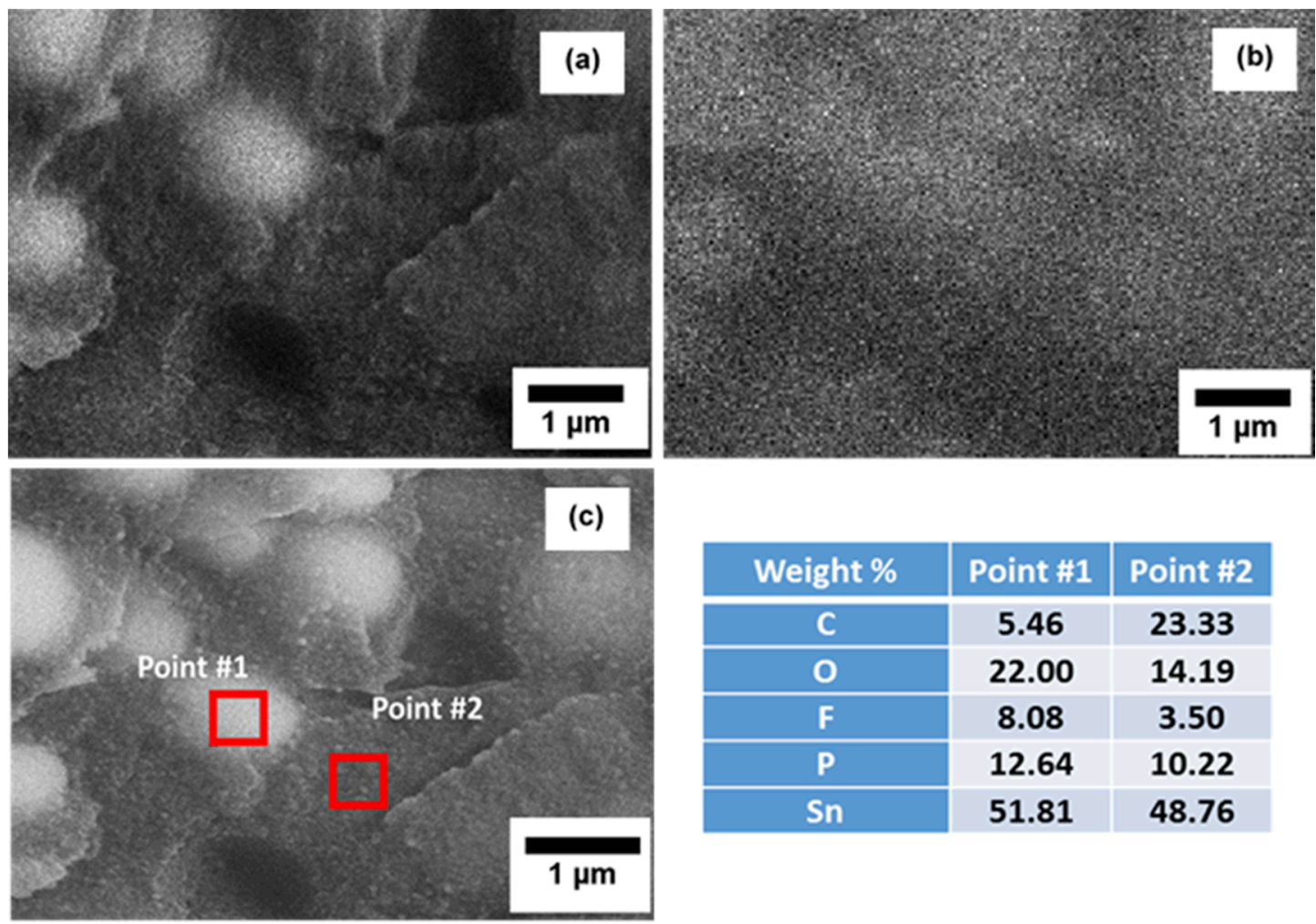

\begin{tabular}{|c|c|c|}
\hline Weight \% & Point \#1 & Point \#2 \\
\hline C & 5.46 & 23.33 \\
\hline O & 22.00 & 14.19 \\
\hline F & 8.08 & 3.50 \\
\hline P & 12.64 & 10.22 \\
\hline Sn & 51.81 & 48.76 \\
\hline
\end{tabular}

Fig. 5. (a) SEM image and EDX mapping images of (b) phosphorous (black background and white spot for each element) on the fracture surface of $15 \mathrm{wt} \%$ Pglass/PET hybrids, and (c) elemental distribution analysis in two different regions in the hybrids. 


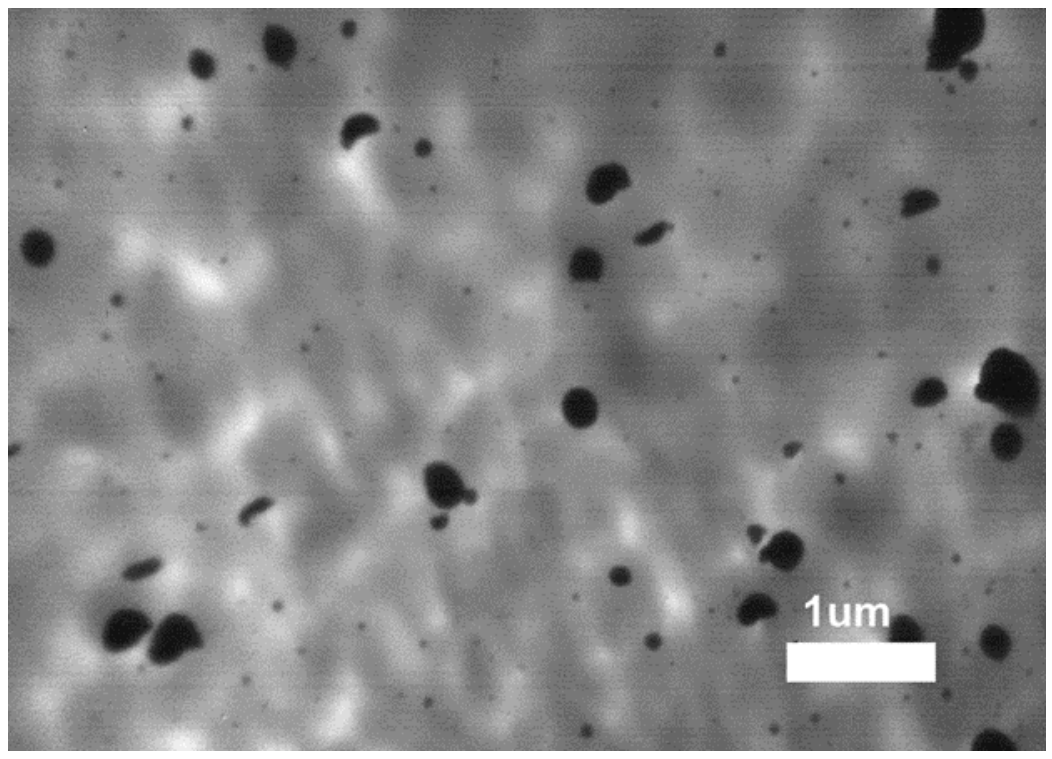

Fig. 6. TEM image of nano- and micro-scale dispersed Pglass particles in the $5 \mathrm{wt} \%$ Pglass/PET hybrids (black spots: Pglass particles, white/gray area: PET polymer). 

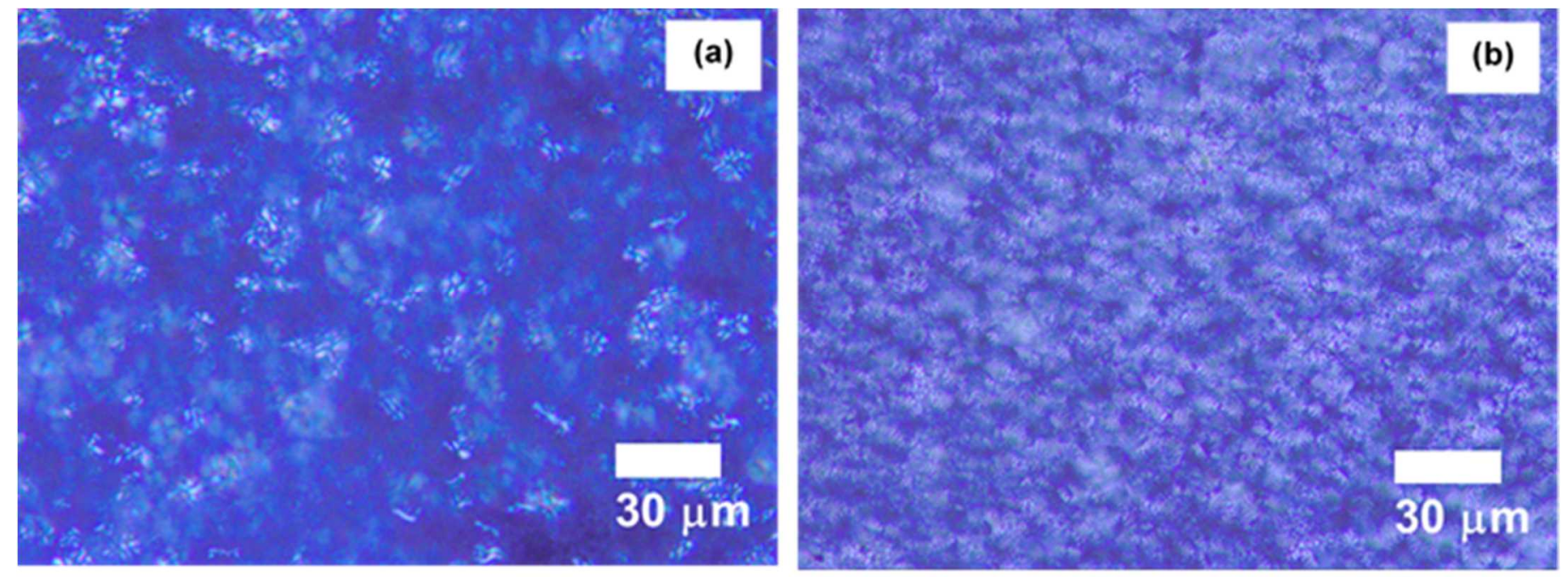

Fig. 7. POM pictures of (a) pure PET and (b) 10 wt\%Pglass/PET hybrids isothermally crystallized at $226^{\circ} \mathrm{C}$ after rapid cooling to crystallization temperature from the melting state at $280^{\circ} \mathrm{C}$. 

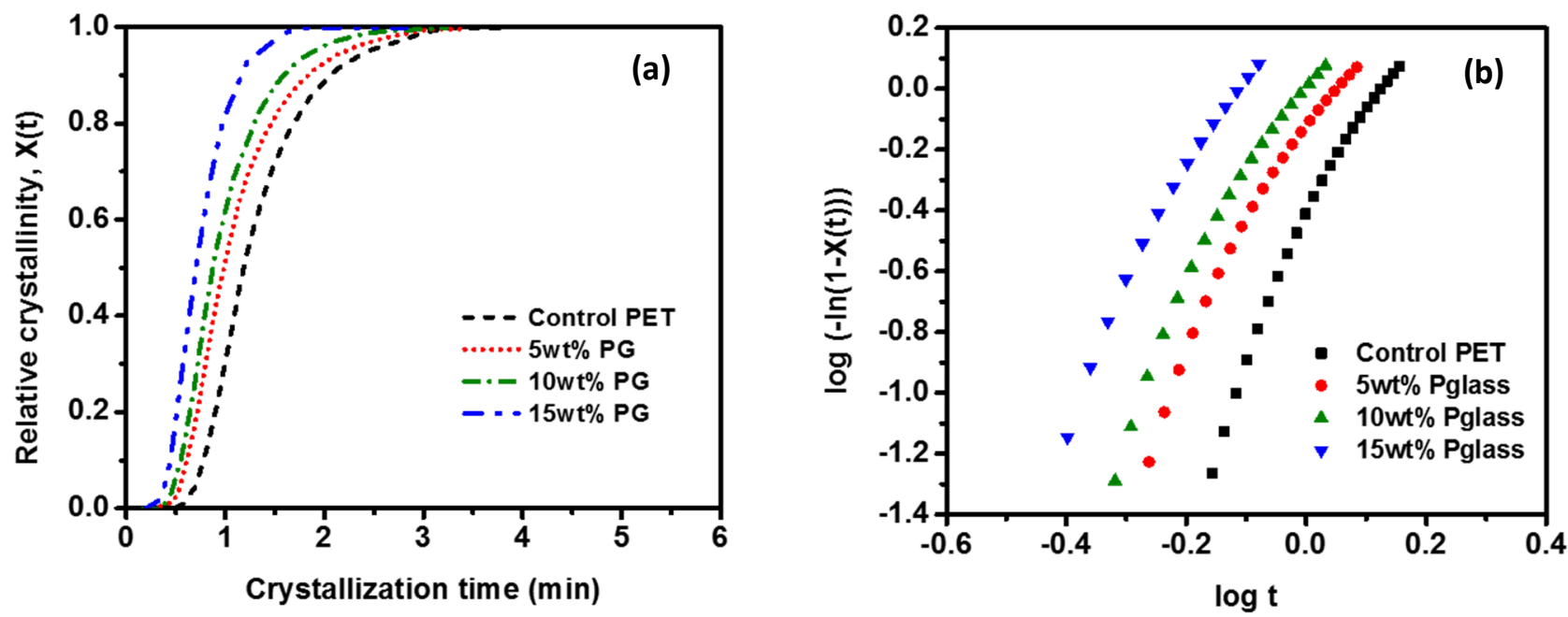

Fig. 8. (a) Plots of relative crystallinity $X(t)$ versus crystallization time (min) and (b) Avrami plot (linear portion, $5 \%<X(t)<70 \%$ crystallinity) of $\log \{-\ln (1-X(t))\}$ versus $\log t$ for isothermal crystallization for four different concentrations of Pglass in the PET matrix hybrid samples. 

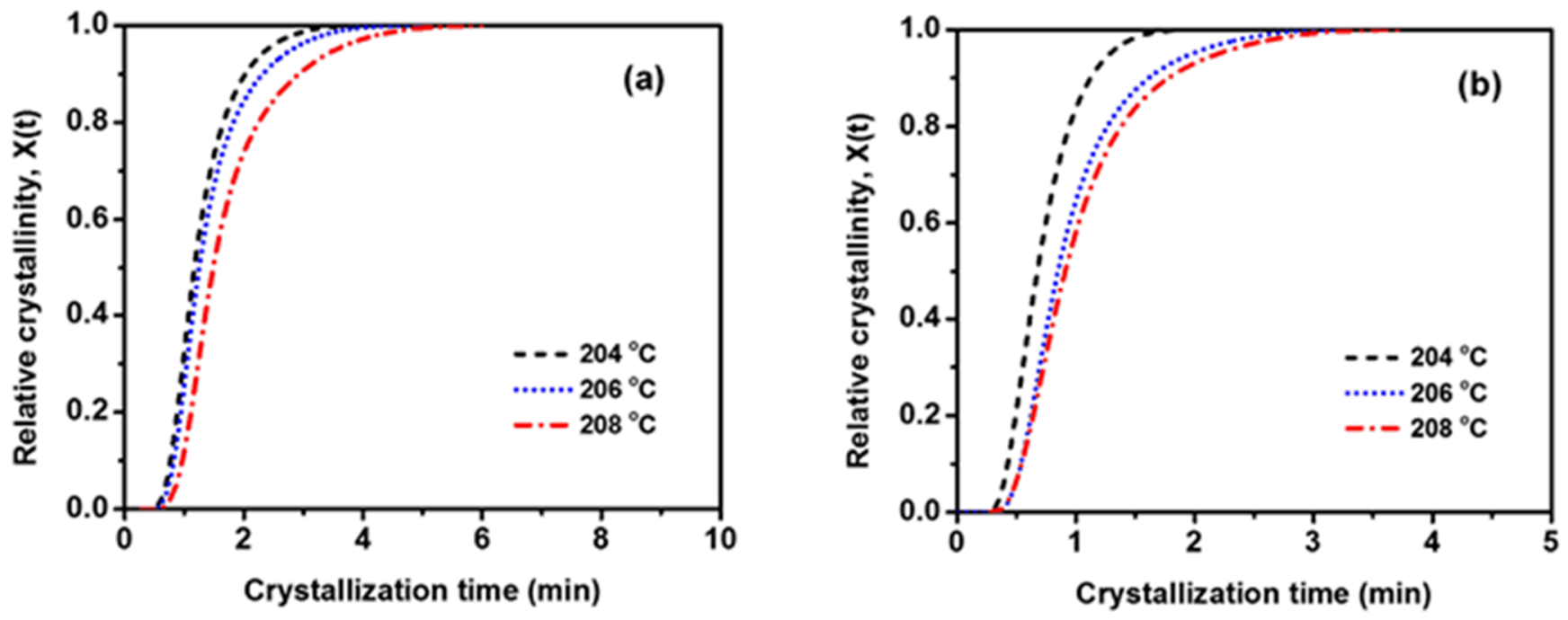

Fig. 9. Relative crystallinity $X(t)$ versus crystallization time (min) for crystallization of (a) control PET and (b) Pglass/PET hybrid samples (15 wt\%Pglass) at the indicated temperatures. 

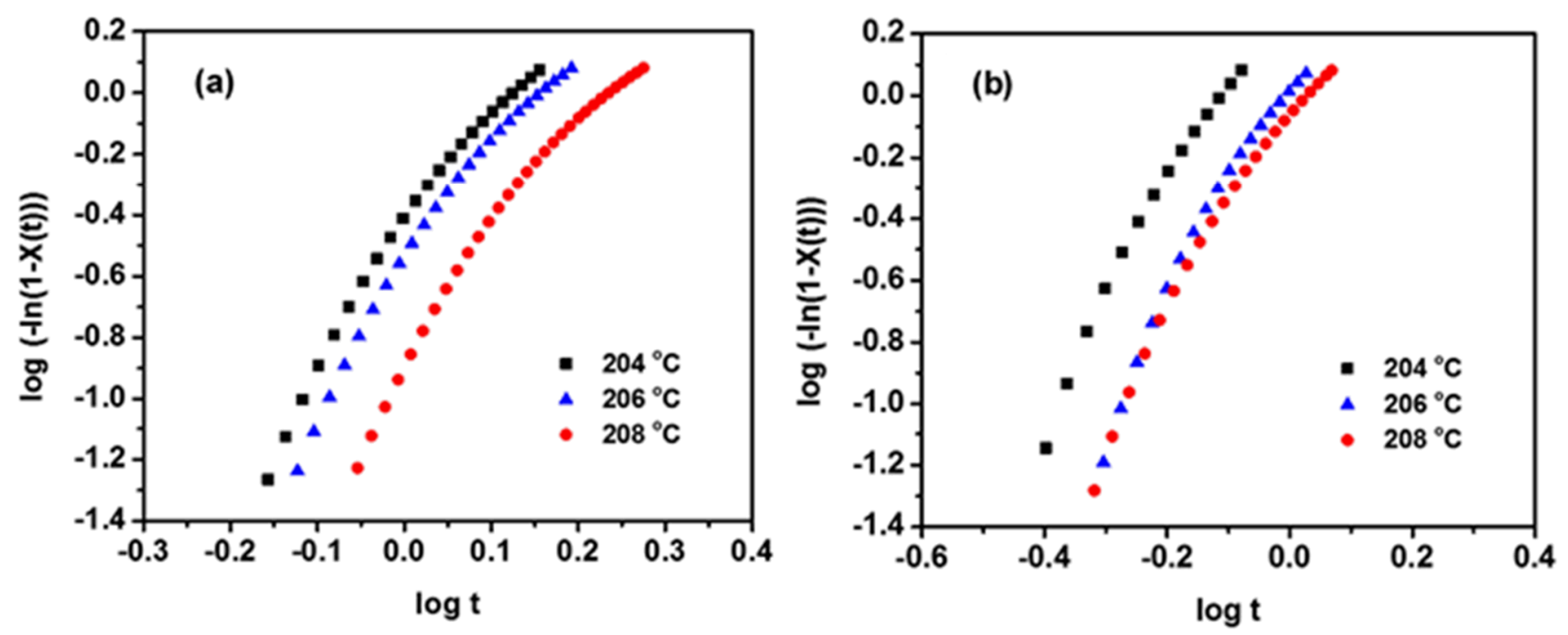

Fig. 10. Avrami plot (linear portion, $5 \%<X(t)<70 \%$ crystallinity) of $\log \{-\ln (1-X(t))\}$ versus log $t$ for isothermal crystallization of (a) control PET and (c) $15 \mathrm{wt} \%$ Pglass/PET hybrids at the indicated temperature. 

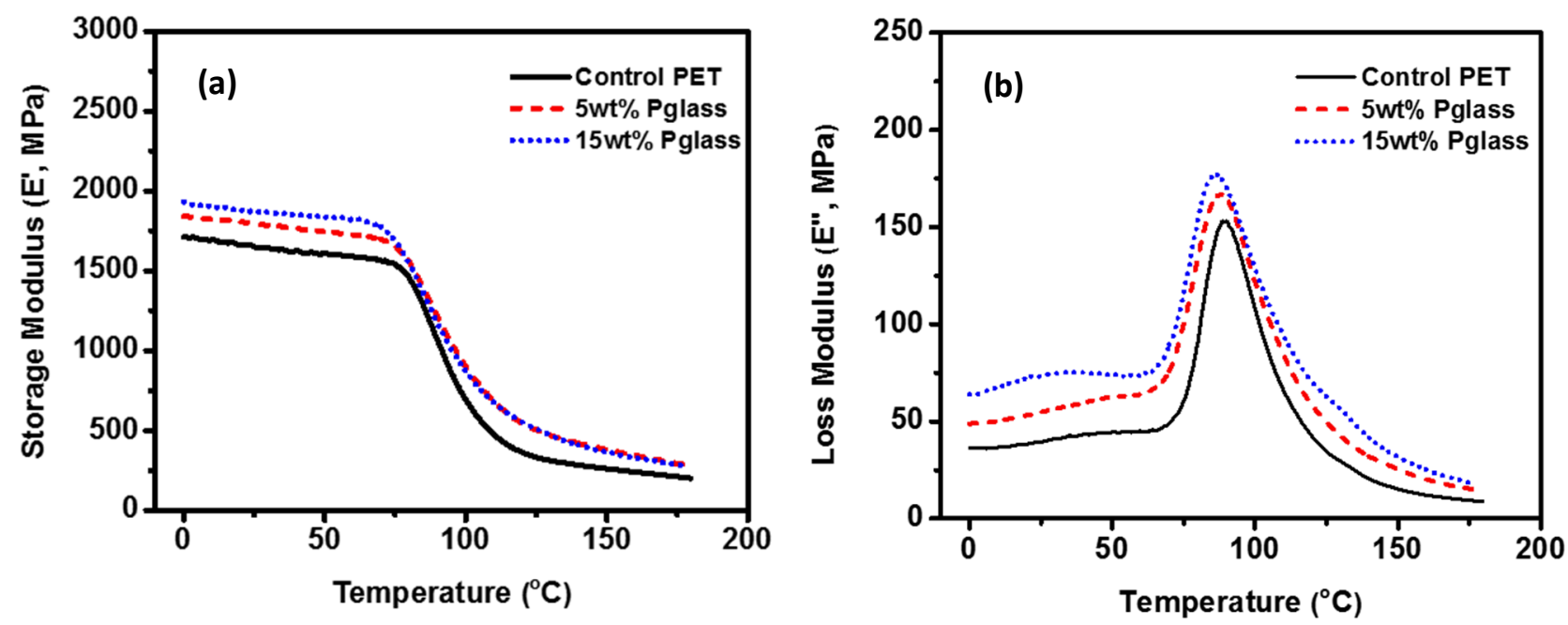

Fig. 11. The effect of the Pglass concentration on (a) storage and (b) loss moduli of the PET and its hybrids incorporating Pglass. 

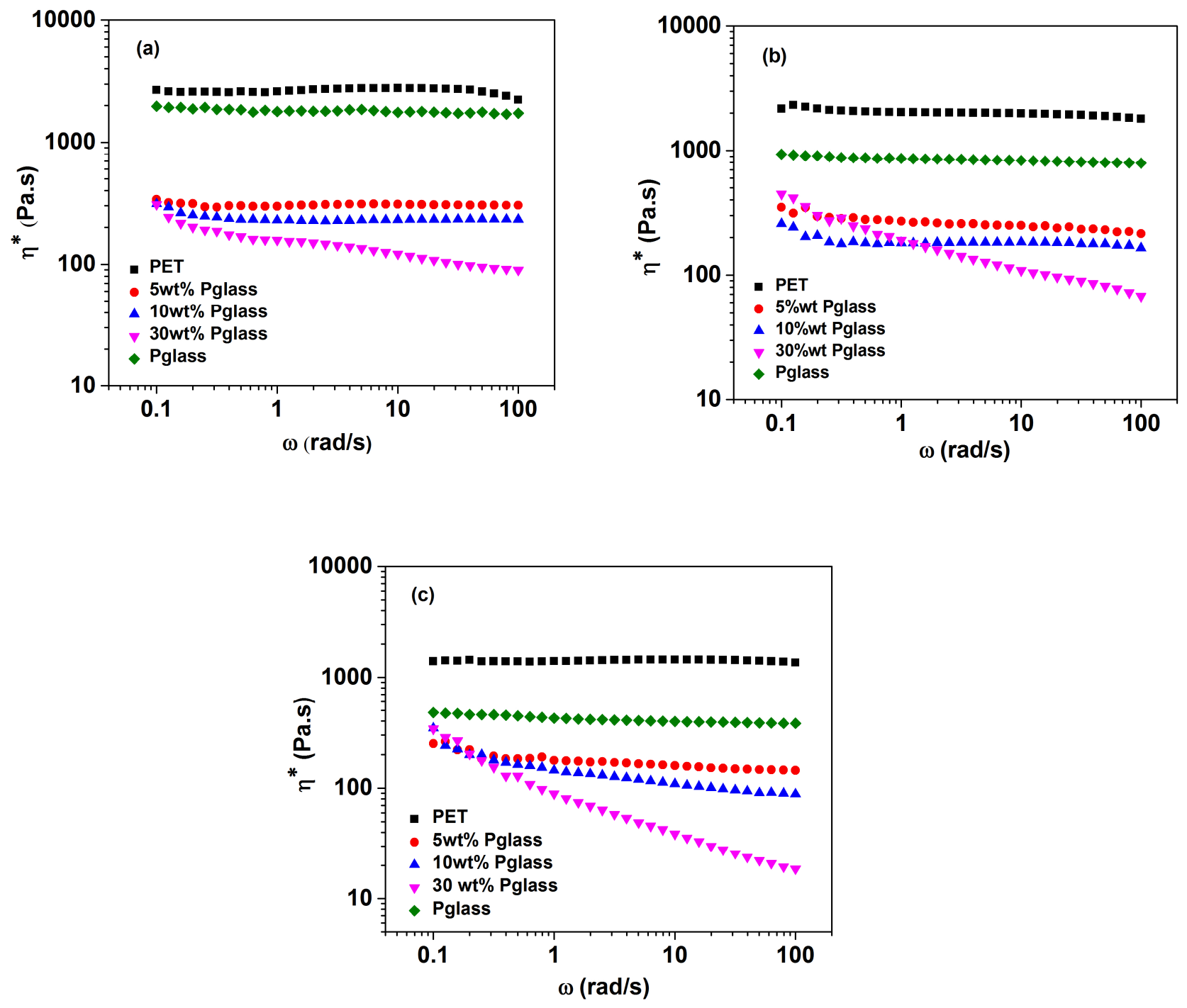

Fig 12. Variation of complex viscosity versus frequency for PET, Pglass and Pglass/PET hybrids at (a) $255^{\circ} \mathrm{C}$, (b) $265^{\circ} \mathrm{C}$ and (c) $280^{\circ} \mathrm{C}$. 

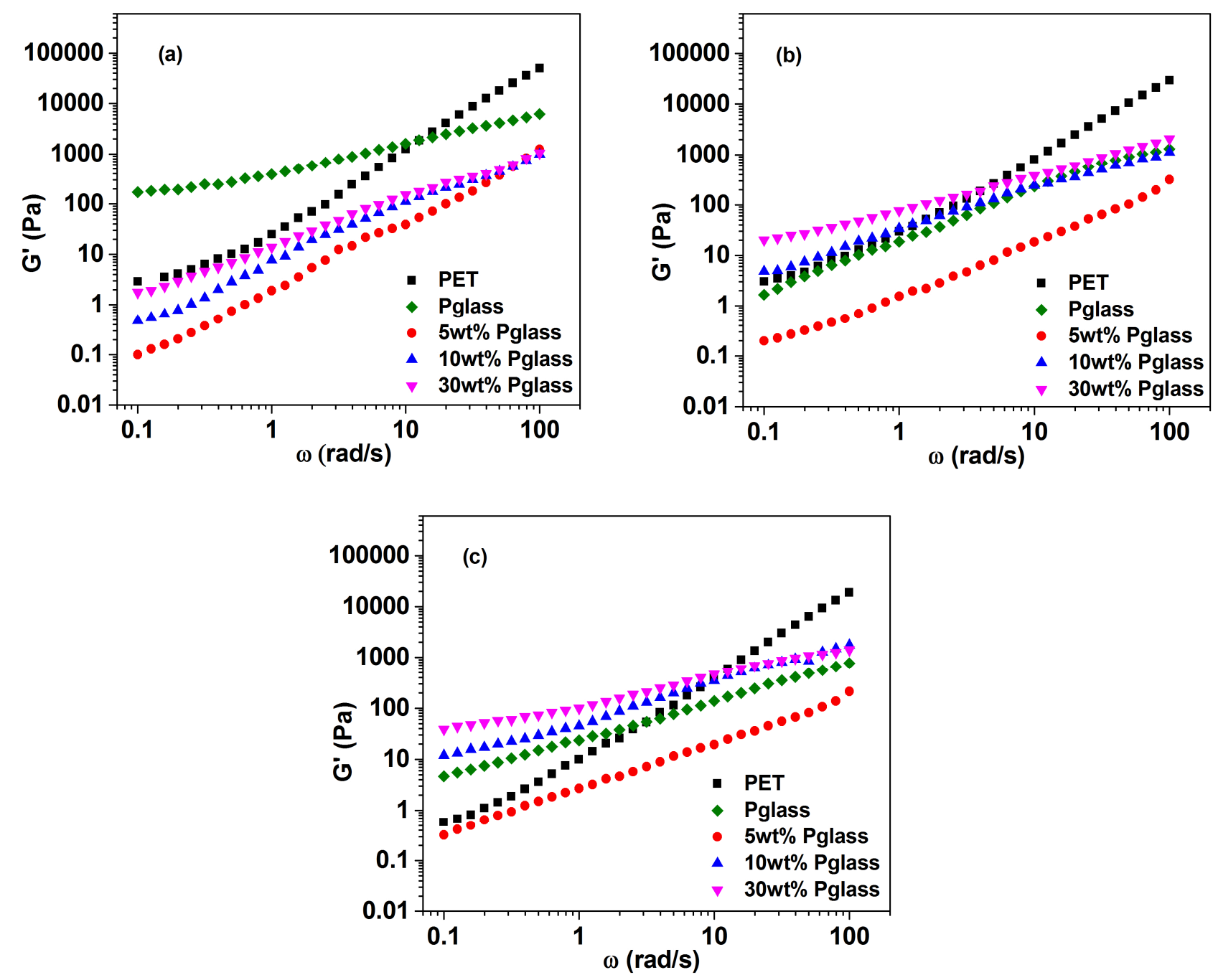

Fig 13. Variation of storage modulus versus frequency for PET, Pglass and Pglass/PET hybrids at (a) $255^{\circ} \mathrm{C}$, (b) $265^{\circ} \mathrm{C}$ and (c) $280^{\circ} \mathrm{C}$. 

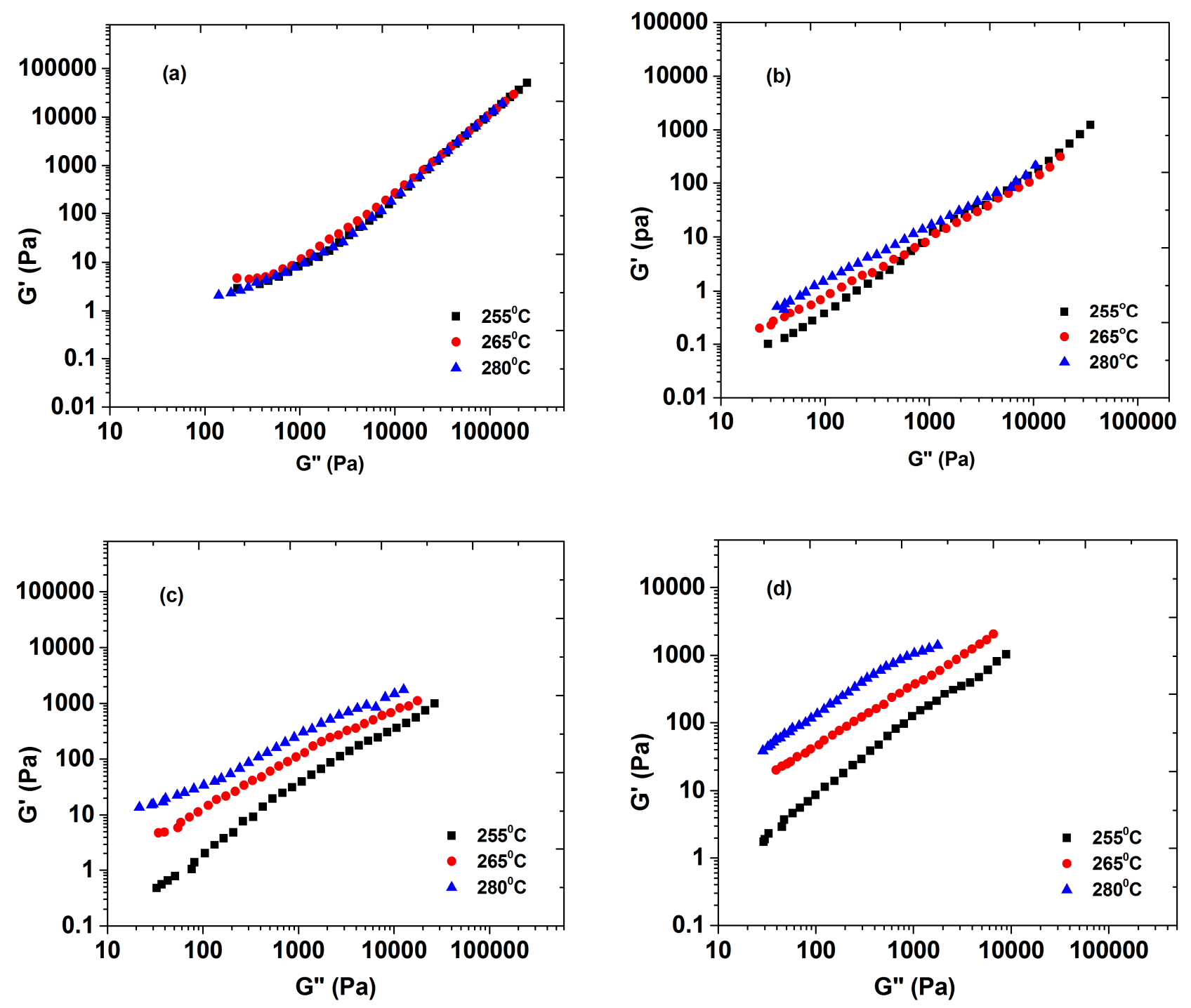

Fig 14. Han plots for (a) PET, (b) 5\% Pglass, (c) 10\% Pglass and (d) $30 \%$ Pglass hybrids at three experimental temperatures of $255^{\circ} \mathrm{C}, 265^{\circ} \mathrm{C}$ and $280^{\circ} \mathrm{C}$. 
(a)

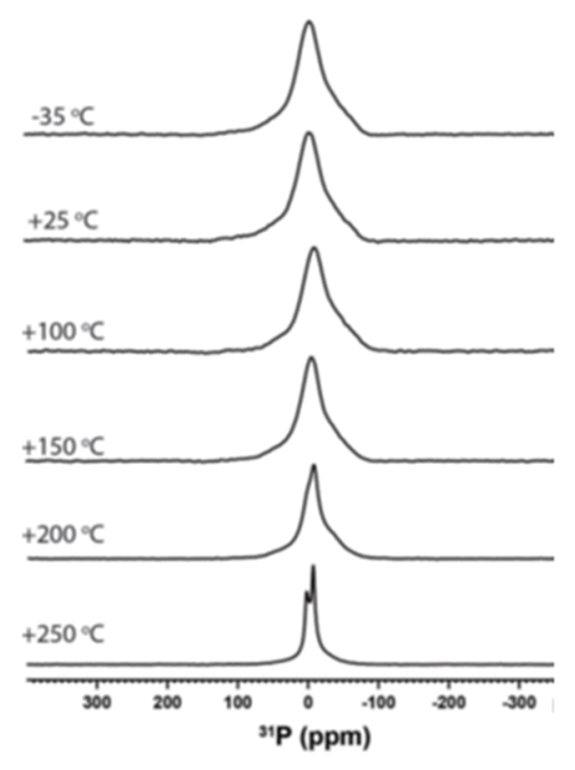

(b)

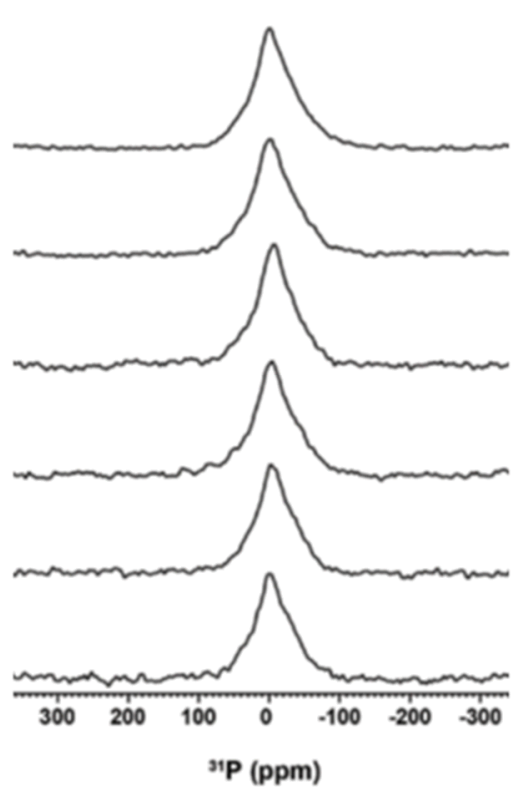

(c)

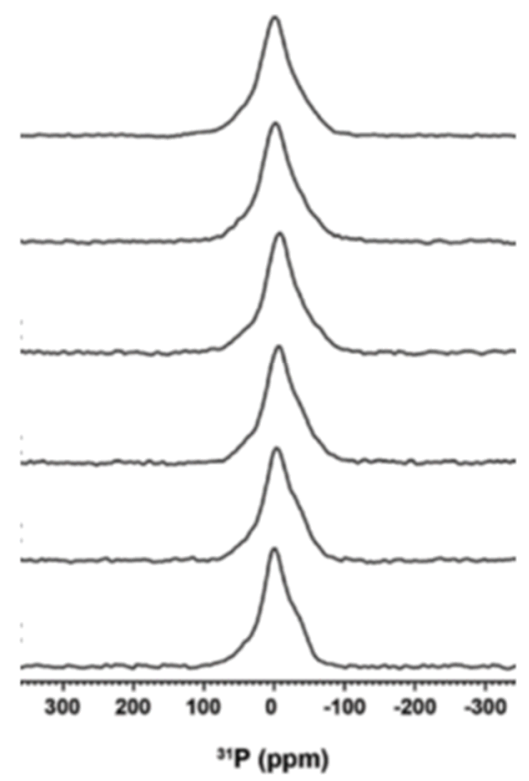

Fig 15. ${ }^{31} \mathrm{P}$ variable-temperature static NMR spectra for (a) pure Pglass, (b) $10 \mathrm{wt} \%$ Pglass, and (c) 50 wt\% Pglass hybrids. 


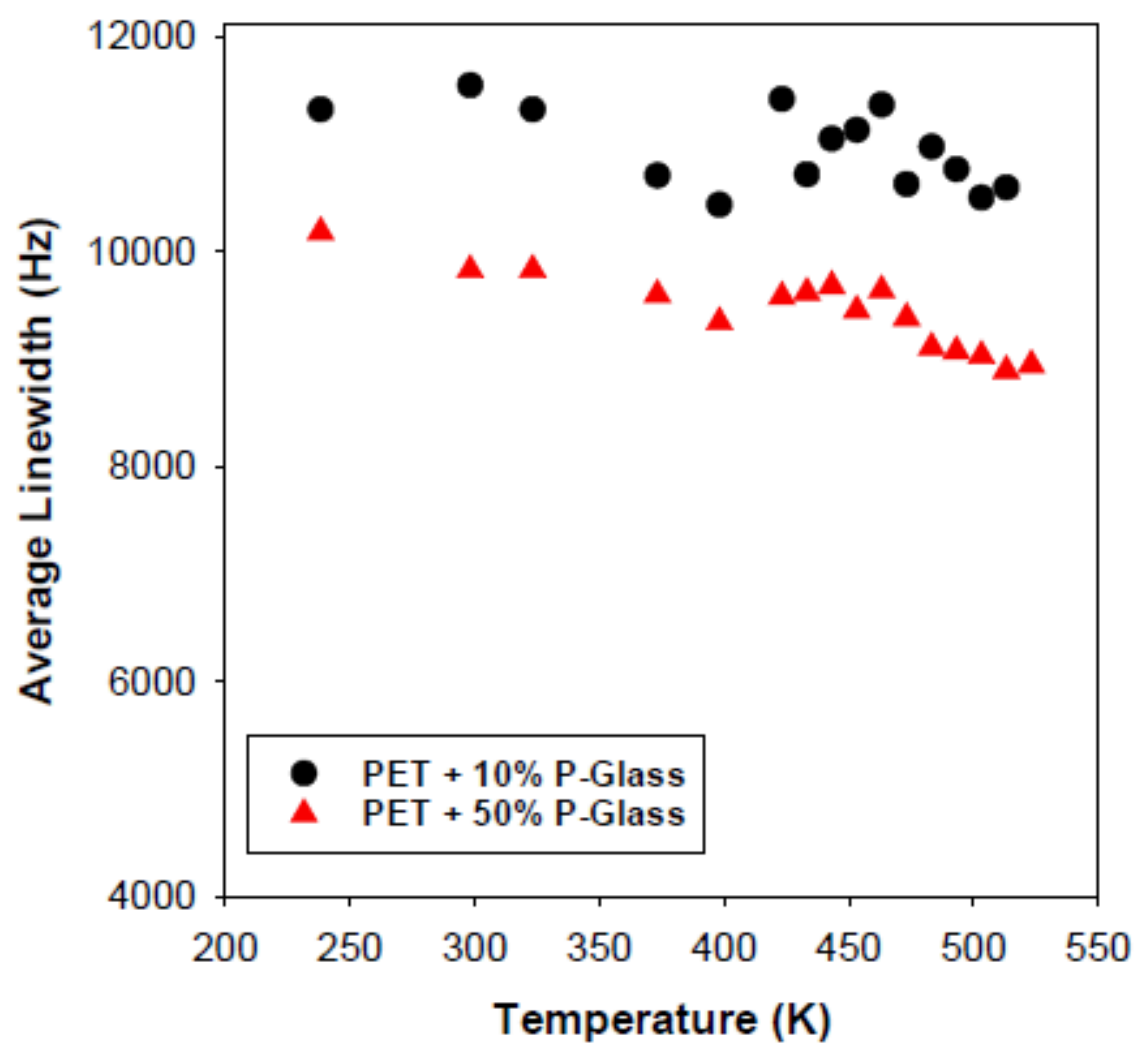

Fig 16. Average ${ }^{31} \mathrm{P}$ linewidth of $10 \mathrm{wt} \%$ and $50 \mathrm{wt} \%$ Pglass hybrids as a function of temperature. 


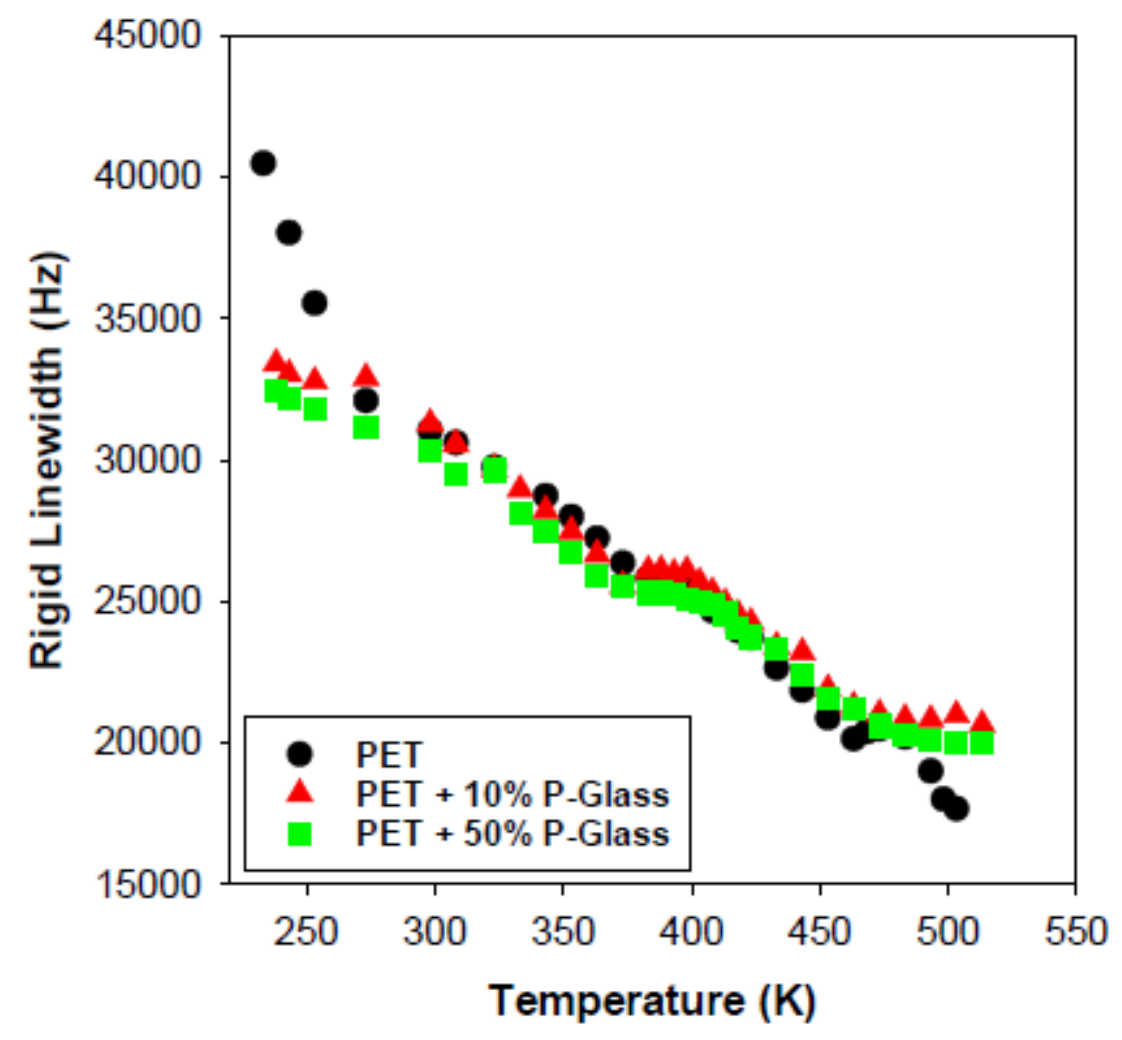

Fig 17. Average ${ }^{1} \mathrm{H}$ rigid linewidth of control PET, $10 \mathrm{wt} \%$ and $50 \mathrm{wt} \%$ Pglass samples as a function of temperature. 


\section{Tables}

Table 1. Kinetic parameters from Avrami analysis for the isothermal crystallization of the Pglass/PET hybrids incorporating various concentration of Pglass.

\begin{tabular}{|c|c|c|c|c|c|c|}
\hline Sample & $\left.\mathrm{T}_{\mathrm{c}}{ }^{\circ}{ }^{\mathrm{C}} \mathrm{C}\right)$ & $\mathrm{n}$ & $\mathrm{K}\left(\mathrm{min}^{-1}\right)$ & $\mathrm{t}_{\max }(\min )$ & $\mathrm{t}_{1 / 2}(\mathrm{~min})$ & $\mathrm{G}\left(\mathrm{min}^{-1}\right)$ \\
\hline Control PET & 204 & 4.113 & 0.339 & 1.216 & 1.170 & 0.855 \\
\hline 5wt\%Pglass/PET & 204 & 3.546 & 0.730 & 0.995 & 0.967 & 1.034 \\
\hline 10wt\%Pglass/PET & 204 & 3.621 & 1.128 & 0.885 & 0.857 & 1.167 \\
\hline 15wt\%Pglass/PET & 204 & 3.769 & 2.901 & 0.695 & 0.677 & 1.477 \\
\hline
\end{tabular}

Table 2. Kinetic parameters from Avrami analysis for the isothermal crystallization of the control

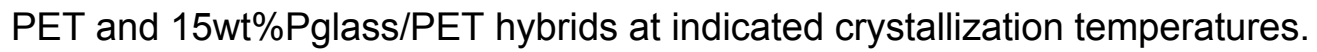

\begin{tabular}{|c|c|c|c|c|c|c|}
\hline & $\left.\mathrm{T}_{\mathrm{c}}{ }^{\circ} \mathrm{C}\right)$ & $\mathrm{n}$ & $\mathrm{K}\left(\mathrm{min}^{-1}\right)$ & $\mathrm{t}_{\max }(\mathrm{min})$ & $\mathrm{t}_{1 / 2}(\mathrm{~min})$ & $\mathrm{G}\left(\mathrm{min}^{-1}\right)$ \\
\hline \multirow{4}{*}{ Control PET } & 204 & 4.113 & 0.339 & 1.216 & 1.170 & 0.855 \\
\cline { 2 - 7 } & 206 & 4.056 & 0.256 & 1.305 & 1.253 & 0.798 \\
\cline { 2 - 7 } & 208 & 3.877 & 0.135 & 1.552 & 1.487 & 0.672 \\
\hline \multirow{3}{*}{ 15wt\%Pglass/PET } & 204 & 3.769 & 2.901 & 0.695 & 0.677 & 1.477 \\
\cline { 2 - 7 } & 206 & 3.700 & 1.172 & 0.880 & 0.850 & 1.176 \\
\cline { 2 - 7 } & 208 & 3.302 & 0.887 & 0.930 & 0.910 & 1.099 \\
\hline
\end{tabular}

